\title{
Complutum
}

ISSN: 1131-6993

\section{Los cascos con cresta del Bronce Final de la Península Ibérica y la segunda fase de las estelas del Suroeste con espejo y casco (1275-1200 AC)}

\author{
Alfredo Mederos Martín ${ }^{1}$ \\ Recibido: 27 de agosto de 2019 / Aceptado: 5 de noviembre de 2019
}

"Trasimedes entregó al Tidida [Diomedes, rey de Argos, hijo de Tideo, rey de Etolia] una espada (...) y un escudo; y en la cabeza se caló un morrión de piel de toro sin crestón ni penacho, que se llama gorro" (Hom., Il., X, 255-258).

\begin{abstract}
Resumen. A pesar de la escasez de cascos metálicos en la Península Ibérica, con seguridad sólo presentes en la ría de Huelva y quizás uno muy fragmentado en Vila Cova de Perrinho (Beira Litoral), ha ido incrementándose en los últimos años el número de cascos en estelas del Suroeste que nos permiten valorar mejor un elemento fundamental de la panoplia del guerrero y una posesión muy preciada. Su análisis indica que aparecen, junto a los espejos, en una segunda fase de las estelas del Suroeste, y se añaden a las estelas de iconografía tripartita con escudo, lanza y espada, las cuales que debieron comenzar hacia el 1325-1300 AC. Los primeros cascos cónicos apuntados con cresta convexa de tipo Biebesheim, conservados completos en Fundão, Santa Ana de Trujillo o Aldeia Velha, cabe situarlos hacia el 1275-1200 AC, asociados con espadas de enmangue rectangular que podrían ser de tipo Rosnöen. Estos elementos sugieren la llegada simultánea de influencias atlánticas y mediterráneas. La fase siguiente corresponde a estelas con antropomorfo debajo del escudo con escotadura en V de tipo Herzsprung y la presencia de espadas pistiliformes, caso de Cabeza de Buey I o Cabañas del Castillo durante el Bronce Final IIB, 1225-1150 AC. La etapa posterior es asignable a estelas donde el escudo y el antropomorfo tienen la misma importancia, perdurando las espadas pistiliformes. El esquematismo de algunas representaciones crea la duda si ya se introducen los primeros cascos cónicos apuntados con cresta cóncava de tipo Bernières d'Ailly en Zarza de Montánchez o Las Herencias I, durante el Bronce Final IIC, 1150$1050 \mathrm{AC}$. La fase final, en estelas donde el antropomorfo tiene un papel preeminente, las representaciones de cascos cónicos apuntados con cresta cóncava son muy esquemáticas en estelas de Setefilla o Ategua, durante el Bronce Final IIIA, 1050-950 AC.
\end{abstract}

Palabras clave: Península Ibérica; estelas del Suroeste; Bronce Final; cascos redondos con cresta; cascos triangulares con cresta.

\section{[en] The crested helmets of the Late Bronze Age of the Iberian Peninsula and the second phase of the South-West stelae with mirror and helmet (1275-1200 BC)}

Abstract. Despite the shortage of metal helmets in the Iberian Peninsula, surely only present in the Huelva estuary and perhaps a very fragmented one in Vila Cova de Perrinho (Beira Litoral), the number of helmets in stelae of the Southwest that allow us to better assess a fundamental element of the warrior's panoply and a very precious possession. His analysis indicates that they appear, at the same time as the mirrors, in a second phase of the stelae of the Southwest, and are added to the stelae of tripartite iconography with shield, spear and sword, which should have started around 1325-1300 BC. The first conical helmets with convex crested type Biebesheim, preserved complete in Fundão, Santa Ana de Trujillo or Aldeia Velha, can be placed around 1275-1200 BC, associated with a rectangular pommel in swords that could be of the Rosnöen type. These elements suggest the simultaneous arrival of Atlantic and Mediterranean influences. The next phase corresponds to stelae with human figure under the V-notched Herzsprung-type shield and the presence of pistiliform swords, case of Cabeza de Buey I or Cabañas del Castillo during the Late Bronze Age IIB, 1225$1150 \mathrm{BC}$. The next stage is assignable to stelae where the shield and the anthropomorph have the same importance, enduring the pistiliform swords. The schematism of some helmets representations creates doubt if the first conical helmets with concave crest type Bernières d'Ailly are already introduced in Zarza de Montánchez or Las Herencias I,

1 Departamento de Prehistoria y Arqueología, Facultad de Filosofía y Letras, Universidad Autónoma de Madrid Campus de Cantoblanco, 28.049 Madrid.

Email: alfredo.mederos@uam.es https://orcid.org/0000-0002-0036-7940 
during the Late Bronze Age IIC, 1150-1050 BC. The final phase, in stelae where the human figure has a preeminent role, the representations of conical helmets with concave crest are very schematic in stelae of Setefilla or Ategua, during the Late Bronze Age IIIA, 1050-950 BC.

Keywords: Iberian Peninsula; South-West stelae; Late Bronze Age; rounded crested helmets; triangular crest helmets.

Sumario. 1. Introducción. 2. Cascos metálicos en depósitos de la Península Ibérica. 3. Cascos cónicos apuntados con cresta convexa en la segunda fase de las estelas del Suroeste. 4. Estelas fragmentadas que pudieron tener casco cónico con cresta. 5. Estelas con escudo central y antropomorfo por debajo, con espada pistiliforme cerca de la mano, que presentan cascos cónicos apuntados con cresta. 6. Estelas con escudo y antropomorfo, de similar importancia, que presentan cascos cónicos apuntados con posible cresta. 7. Estelas con antropomorfo en posición central que presentan cascos cónicos apuntados con cresta cóncava. 8. Hileras de puntos sobre la cabeza interpretadas como casco o tocado. 9. Representaciones dudosas de cascos. 10. Discusión. 11. Conclusiones. 12. Agradecimientos. 13. Bibliografía.

Cómo citar: Mederos Martín, A. (2019). Los cascos con cresta del Bronce Final de la Península Ibérica y la segunda fase de las estelas del Suroeste con espejo y casco (1275-1200 AC). Complutum, 30 (2): 273-311.

\section{Introducción}

Los cascos metálicos son piezas excepcionales en el registro arqueológico del Bronce Final Atlántico de la Península Ibérica. En general, tanto en Europa como en España son hallazgos muy raros que aparecen vinculados a depósitos rituales en tierra o en ríos y apenas aparecen en enterramientos con la excepción de Italia. Por ello, la información adicional que aporta la iconografía de las estelas es fundamental para precisar mejor el momento de su aparición, desarrollo y cronología. Por otra parte, pone en evidencia que no se trata de elementos tan excepcionales en la panoplia del guerrero en la Península Ibérica.

Nuestro objetivo es una revisión de todas las estelas que parecen presentar iconografía de cascos, las 16 que creemos más probables, y otros 5 casos que consideramos más discutibles pero han sido propuestas por otros investigadores.

En la descripción de cada estela se incluirá el municipio y provincia, las dimensiones del soporte, la fecha de entrada en el museo y la discusión en la bibliografía sobre el motivo interpretado como casco.
Finalmente se presenta también una posible secuencia evolutiva de los cascos dentro de las estelas, acorde con la iconografía de los otros motivos representados, y se analizan los paralelos con los cascos metálicos de Europa continental.

\section{Cascos metálicos en depósitos de la Península Ibérica}

Los primeros ejemplares fueron identificados por John Cowen y Hugh Hencken durante el IV Congreso Internacional de Ciencias Prehistóricas y Protohistóricas celebrado en Madrid en 1954, procedentes del pecio o depósito de Huelva, muy fragmentados (Hencken 195556: 228, 225 fig. 1, 227 lám. 1/2), que en un caso, $\mathrm{n}^{\circ} 32.525$, había sido previamente asociado a un posible fragmento de caldero (Almagro Basch 1940: 137). Entre ellos también pudo identificar la punta de la cresta de un casco con fina decoración de líneas paralelas incisas, $n^{\circ} 32.606$ (Hencken 1955-56: 228, 225 fig. 1, 226 lám. 1/1). Este fragmento analizado posteriormente presentaba un $11.83 \%$ de estaño, muy similar al fragmento principal de casco, 11.25\% (Rovira 1995: 47 tabla 14, 52). 


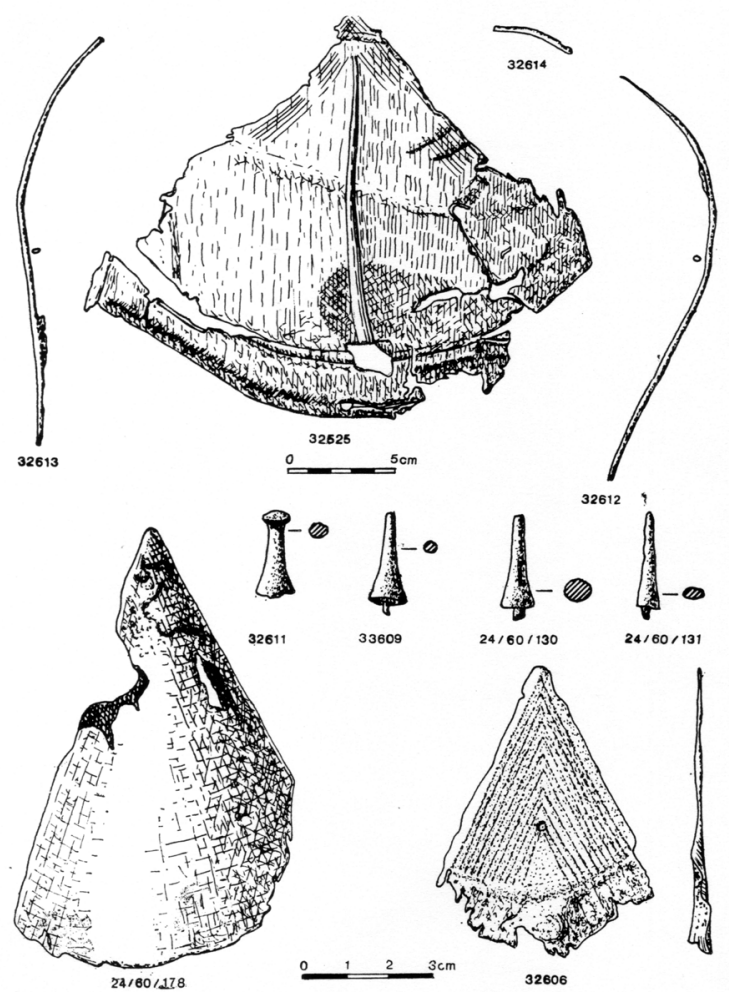

Figura 1a. Cascos de la Ría de Huelva: de cresta cóncava (32.525 + 32.606), cónico apuntado $(24 / 60 / 178)$ y remaches de sujeción o decorativos $(32.611,33.609,24 / 60 / 130$ y 24/60/131) (Almagro Gorbea 1973: 350 fig. 1/1-9).

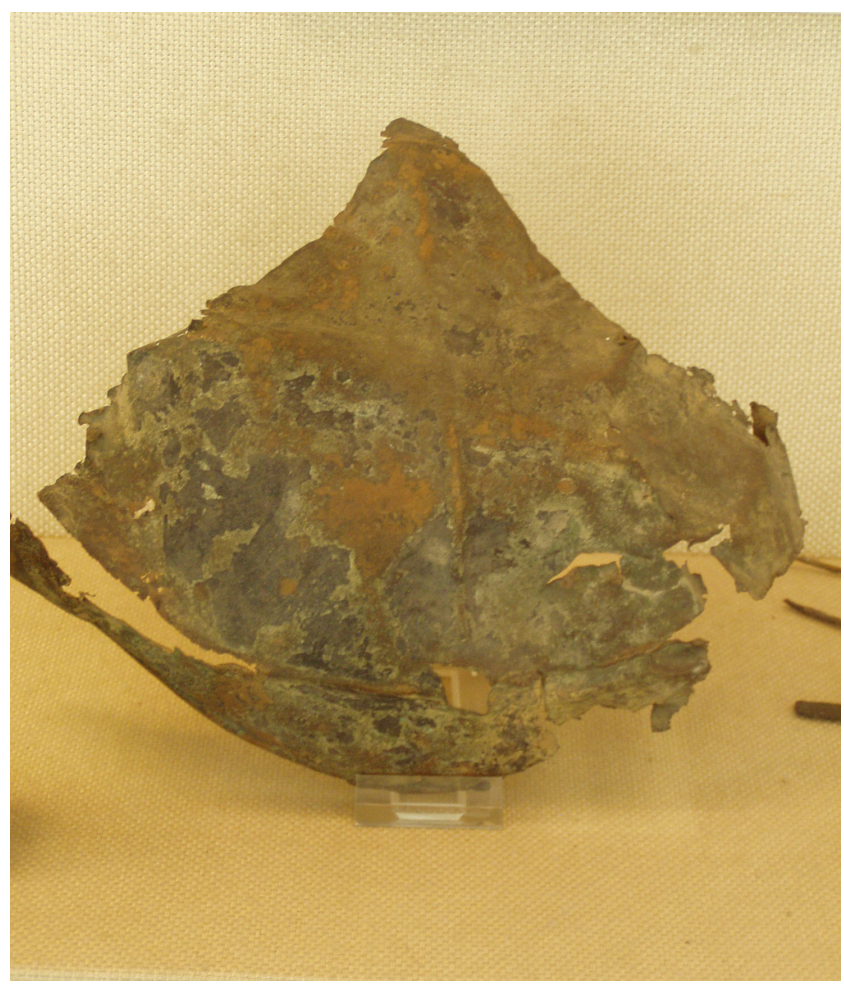

Figura 1b. Casco cónico apuntado con cresta cóncava de la Ría de Huelva, $\mathrm{n}^{\circ}$ inv. 32.525. Museo Arqueológico Nacional, Madrid. Foto: A. Mederos. 


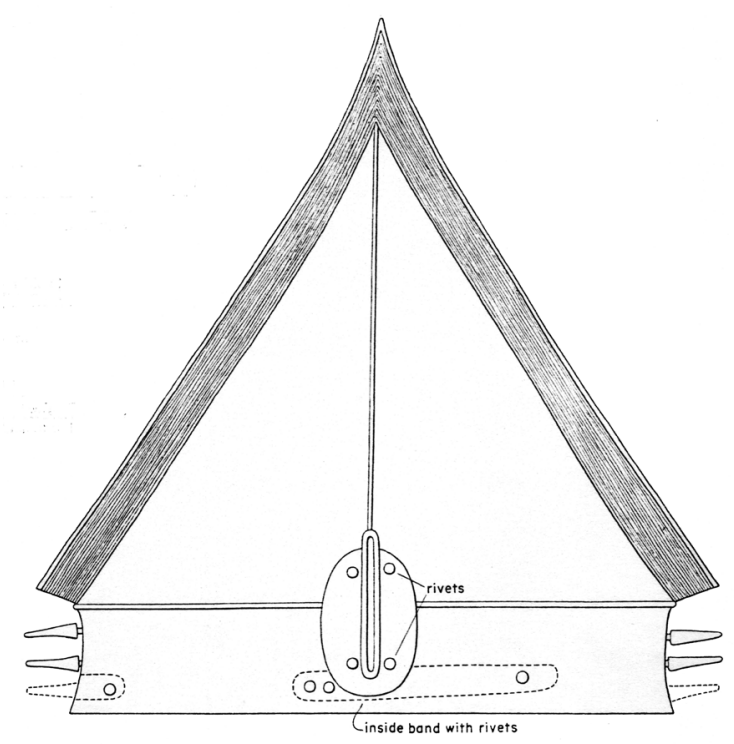

Figura 1c. Casco cónico apuntado con cresta cóncava de Bernières d’Ailly (Calvados, Francia)

(Hencken 1971: 69 fig. 41).

El segundo hallazgo importante fue detectar el extremo superior de un casco cónico apuntado sin cresta, $n^{\circ}$ 24/60/178 (Almagro Basch 1958: lám. 39/273), para el cual no se identificaba ejemplo atlántico (Almagro Gorbea 1973: 351, 350 lám. 1/8, 361 lám. 1) hasta que fue relacionado por Peter Schauer (1983: 185-187, fig. 5a-b; Almagro Gorbea 1989: 281 y 1998: 83 fig. 1b;
Gomá 2018: 69-70) con prototipos asirios a partir de los relieves del palacio de Asurnasirpal II (883-859 a.C) en Nimrud, y en particular ejemplares de Uratu y un casco de Kouklia en Chipre que habría llegado a la islas con las tropas de Sargon II (722-705 a.C.). El análisis metalúrgico del fragmento de Huelva indica un $12.74 \%$ de estaño (Rovira 1995: 47 tabla 14).

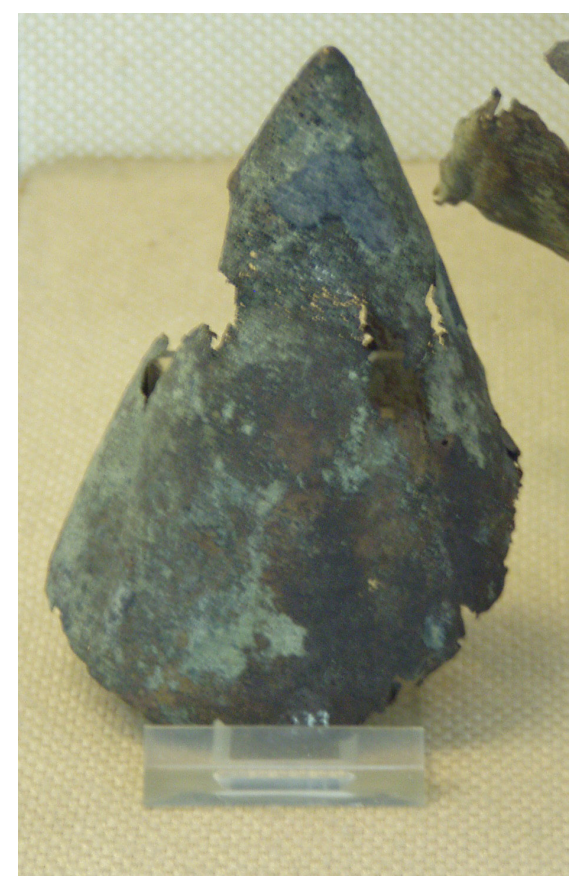

Figura 2a. Casco cónico apuntado de la Ría de Huelva, nº inv. 24/60/178. Museo Arqueológico Nacional, Madrid. Foto: A. Mederos. 


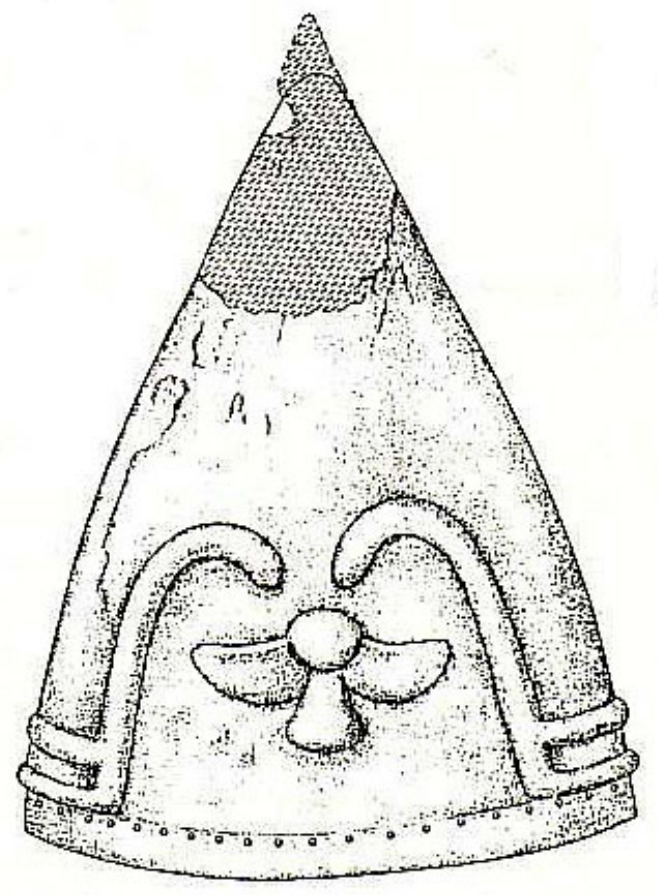

Figura 2b. Superposición del casco cónico apuntado de la Ría de Huelva (24/60/178) con el casco de Kouklia (Chipre) (Schauer 1983: fig. 5).

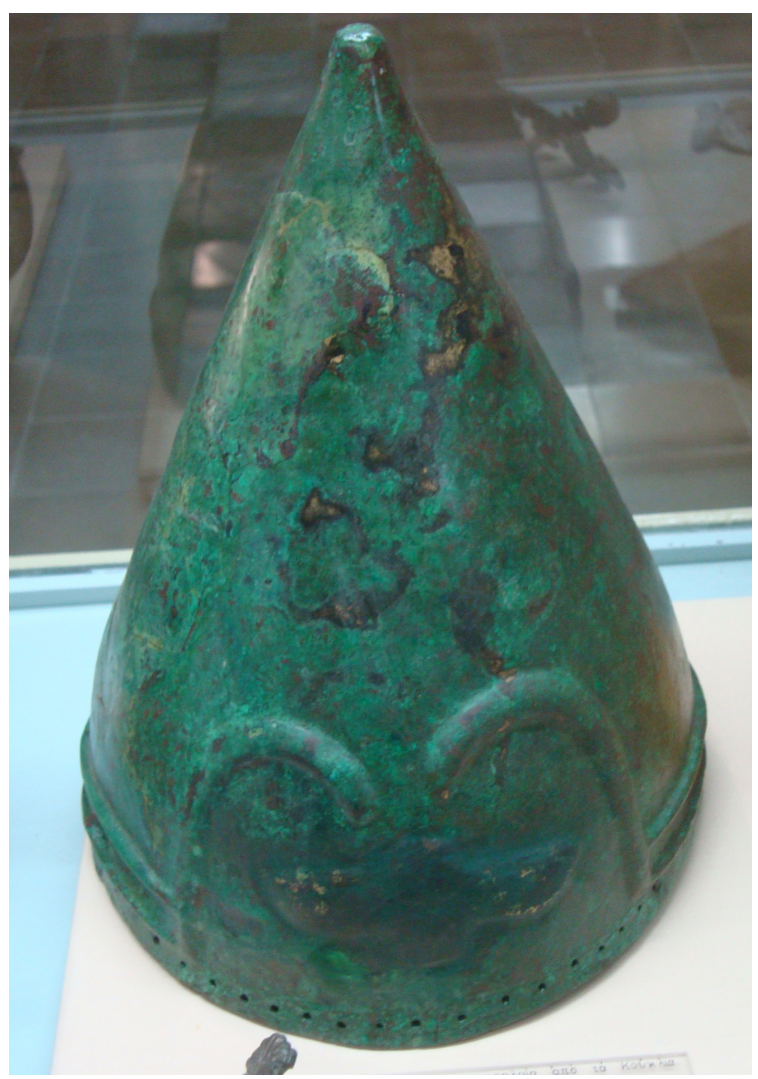

Figura 2c. Casco de la tumba 7-8 de Mavrommatis, Kouklia, antigua Palaeopahos (Chipre), nº inv. 1965/XI-29/62. Museo de Chipre, Nicosia. Foto: A. Mederos. 
Aunque la cronología del depósito o pecio de Huelva está relativamente establecida por 6 dataciones en el siglo X AC, ca. 987-922 AC (Almagro Gorbea 1977: 524-525) en el tránsito del Bronce Final IIIA al Bronce Final IIIB o Hierro I, ca. 950/925 AC (Mederos 1996: 96-98 tabla 1), las representaciones iconográficas asirias corresponden a fechas posteriores. Sin embargo, como Tamás Dezsö (2001: 21 y 2012) señala, el problema es que no existen representaciones de cascos metálicos entre el Obelisco Blanco de Asurnasirpal I (1050-1032 a.C.) y los relieves del palacio de Asurnasirpal II, es decir, durante la segunda mitad del siglo XI y todo el siglo X AC.

El casco de Huelva se asoció por Schauer con una pieza procedente de la tumba 7-8 de Mavrommatis, Kouklia, en la antigua Palaeopahos, sede del santuario de Afrodita, que tiene $24.6 \mathrm{~cm}$ de altura y $21.4 \mathrm{~cm}$ de diámetro. Presenta como decoración un par de arcos a modo de cejas que enmarcan un sol alado. El casco depositado en el Museo de Chipre en Nicosia, $n^{\circ}$ inv. 1965/XI-29/62, ha sido considerado del periodo Chipro-Arcaico, 750-650 AC por Dezsö (1998: 11-12, lám. 6; 2001: 6869 nº 35, lám. 47; Pflug 1988: 34 fig. 9), quien hace la interesante precisión de que debe pro- ceder de un taller del norte de Siria pues no se conocen cascos asirios con un disco alado como motivo decorativo exclusivo (Dezsö 2001: 58).

La revisión del depósito llevó al descubrimiento de varios fragmentos de remaches que sirven para unir en ambos extremos las dos láminas metálicas que conforman un casco apuntado con cresta a la vez que tienen un valor decorativo (Almagro Gorbea 1973: 351, 350 lám. 1/4-7, 361 lám. 1). Estos remaches aparecen también representados en las estelas del Suroeste.

Posteriormente se identificó por André Coffyn (1983: 179 y 1985: 208 lám. 40/10-11; Brandherm 2011: 40) un posible casco metálico a partir de dos pequeños fragmentos de 40 y 45 gr localizados en el supuesto depósito o sepultura de Monte Crasto (Vila Cova de Perrinho, Vale de Cambra, Aveiro, Beira Litoral) (Brandão 1963: 118, lám. 1/9-11; Bottaini y Rodrigues 2011a: 109, 106 fig. 2 y 2011b: 3536, 31 fig. 5) en el Norte de Portugal, cercano a Oporto, pero los fragmentos no han sido objeto de un análisis detallado, aunque el conjunto parece de un momento avanzado del Bronce Final IIC, 1150-1050 AC.

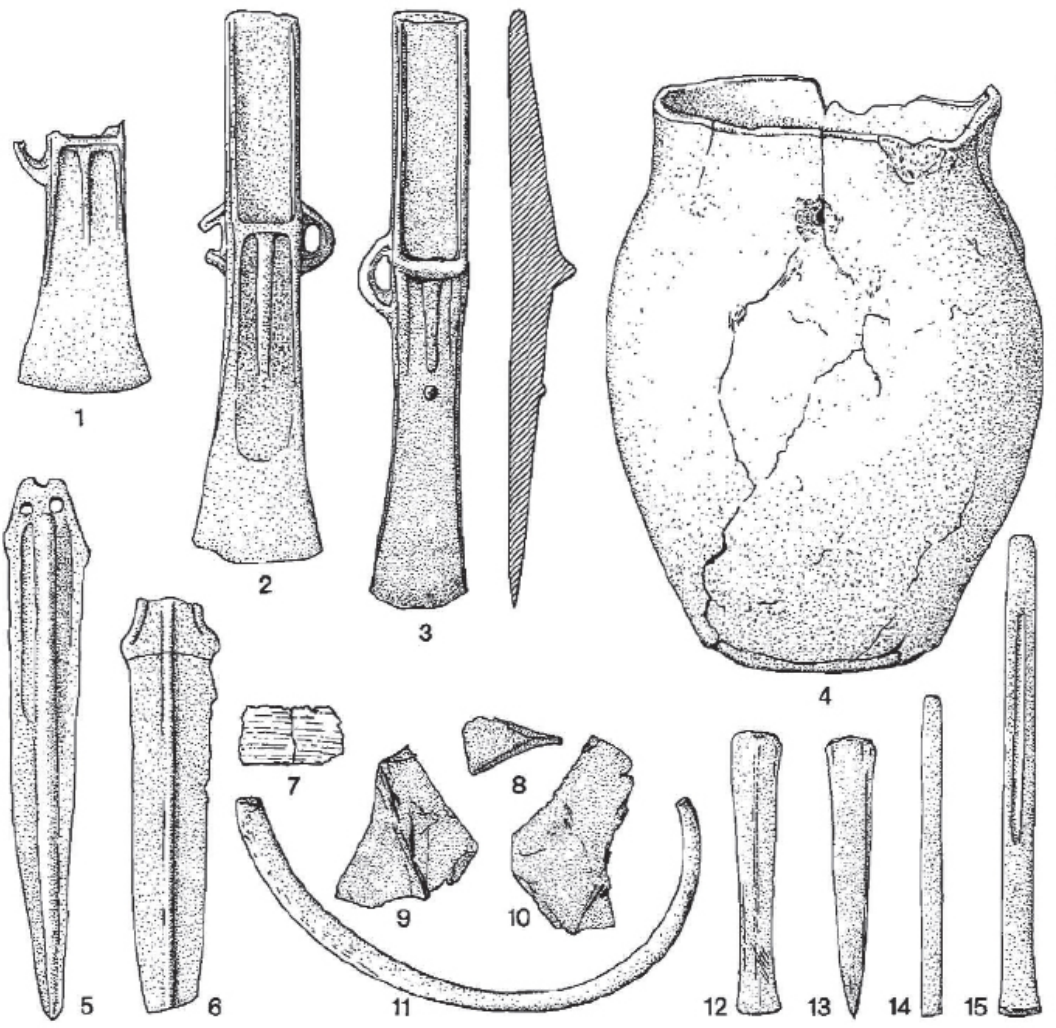

Fig. 3a. Depósito de Monte Crasto con posibles fragmentos de casco (Vila Cova de Perrinho, Aveiro, Beira Litoral, Portugal) (Kalb 1980: 43). 

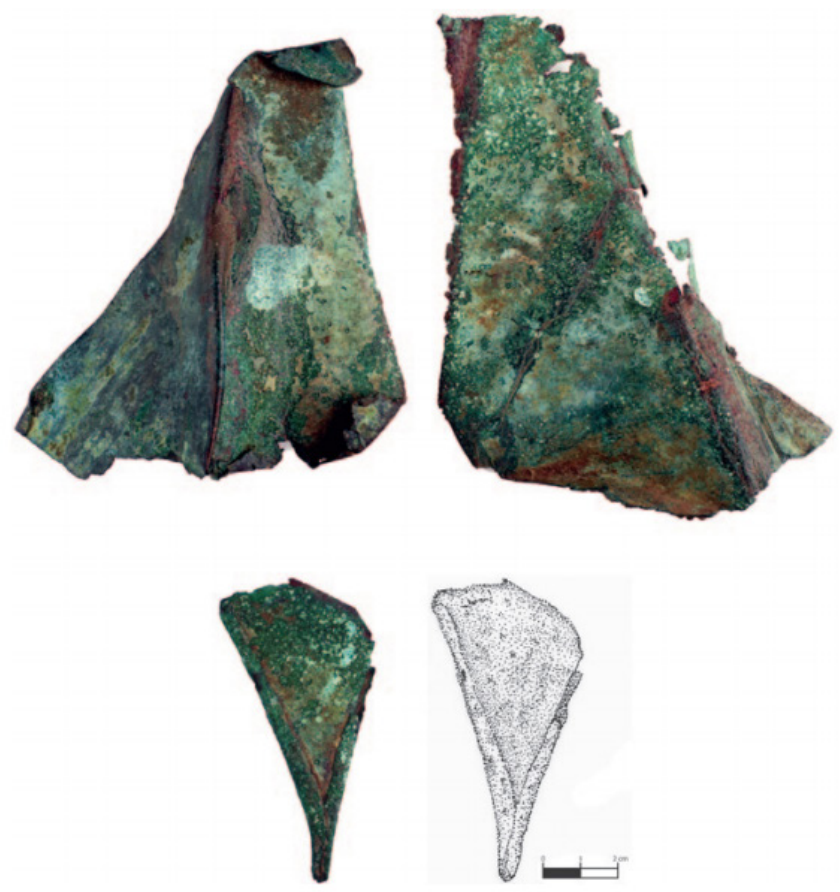

Fig. 3b. Posibles fragmentos de casco de Vila Cova de Perrinho

(Beira Litoral) (Bottaini y Rodrigues 2011b: 31 fig. 5).

Un aspecto importante a tener en cuenta es que creemos que todos los cascos conocidos en la iconografía de las estelas del Suroeste presentan una cresta, tanto en los ejemplares más antiguos de forma cónica y cresta convexa (von Merhart 1940: 15, 17 fig. 3; Brandherm 2011: 42 fig. 2), denominados tipo Biebesheim (Mödlinger 2017: 23 fig. 2.2) como de los más evolucionados, con forma más apuntada en el extremo superior y cresta cóncava (von Merhart 1940: 15, 18 fig. 4), denominados tipo Bernières d'Ailly (Mödlinger 2017: 23 fig. 2.2). No obstante, algunos investigadores han planteado que varias representaciones de cascos en estelas del Suroeste corresponderían al modelo de casco cónico apuntado oriental sin cresta asignables al siglo IX AC, inicialmente en la estela de Herencias y quizás Solana de Cabañas (Almagro Gorbea 1989: 281), ampliado más recientemente a los de Herencias, Almargen, Setefilla y Ategua (Gomá 2018: 68-70).

Tabla 1. Análisis metalúrgicos de los fragmentos de casco del pecio o depósito de Huelva. Los números de cada fragmento en la fig. 1a (Rovira 1995: 47 tabla 14). VCP=Vila Cova de Perrinho (Bottaini y

Rodrigues 2011b: 32 tabla 1). En un primer artículo, ARQ027 y ARQ028 corresponden a dos cinceles y los dos posibles fragmentos de cascos son ARQ034 y ARQ035 (Bottaini y Rodrigues 2011a: 108-109).

\begin{tabular}{|c|c|c|c|c|c|c|c|c|c|}
\hline Inv. & Análisis & $\mathbf{C u}$ & $\mathbf{S n}$ & $\mathbf{P b}$ & $\mathbf{A g}$ & $\mathbf{S b}$ & $\mathbf{A s}$ & $\mathbf{F e}$ & $\mathbf{N i}$ \\
\hline $\mathbf{2 4 / 6 0 / 1 3 0}$ & AA0590 & 80.54 & 17.72 & 0.70 & - & - & 0.08 & 0.11 & 0.22 \\
\hline $\mathbf{2 4 / 6 0 / 1 3 1}$ & AA0591 & 88.90 & 10.92 & - & - & 0.01 & - & 0.04 & 0.14 \\
\hline $\mathbf{2 4 / 6 0 / 1 7 8}$ & AA0587 & 86.93 & 12.74 & - & - & - & - & 0.08 & 0.02 \\
\hline $\mathbf{3 2 5 2 5}$ & AA0585 & 88.26 & 11.25 & 0.23 & - & - & - & 0.06 & trazas \\
\hline $\mathbf{3 2 6 0 6}$ & AA0586 & 88.08 & 11.83 & - & 0.004 & 0.02 & - & 0.03 & 0.01 \\
\hline $\mathbf{3 2 6 1 2}$ & AA0592 & 88.59 & 10.91 & 0.28 & 0.023 & 0.10 & - & 0.04 & 0.04 \\
\hline $\mathbf{3 2 6 1 3}$ & AA0593 & 88.77 & 10.62 & 0.38 & 0.021 & 0.09 & - & 0.05 & 0.06 \\
\hline $\mathbf{3 2 6 1 4}$ & AA0594 & 88.65 & 10.12 & 0.29 & 0.004 & - & - & 0.04 & 0.23 \\
\hline VCP & ARQ027 (34) & 92.3 & 7.7 & - & - & - & - & - & - \\
\hline VCP & ARQ028 (35) & 91.8 & 8.2 & - & - & - & - & - & - \\
\hline
\end{tabular}


3. Cascos cónicos apuntados con cresta convexa en la segunda fase de las estelas del Suroeste

\subsection{Santa Ana de Trujillo}

El primer ejemplo claro de la presencia de cascos de cresta en las estelas del Bronce Final fue sobre la estela de Santa Ana de Truji1 lo (Cáceres) (17), de $1.85 \mathrm{~m}$ de altura y 0.44 $\mathrm{m}$ de ancho, que ingresó en 1942 en el Museo Arqueológico de Badajoz (Ramón y Fernández Oxea 1942: 334-336, fig. 2-3; Almagro Basch 1966: 66-68, fig. 20, lám. 15). Presenta la composición tripartita con lanza en parte superior, escudo central con escotadura en $\mathrm{V}$ exterior y remaches, con una espada en la parte inferior, a la que se añaden elementos nuevos como un casco y un posible espejo (Celestino 2001: 343; Harrison 2004: 213), aunque a este último artefacto Martín Almagro Basch $(1966: 66,68)$ lo considera una fíbula de codo, sin descartar que sea un espejo oval con mango corto. En la primera publicación no se apreció el casco, que fue observado al estudiar Almagro Basch (1966: 66, 68 y 1974b: 219) de nuevo la estela, quien lo identificó como un casco con cimera metálica y un remache a ambos lados, con unas dimensiones bastante realistas, $25.5 \mathrm{~cm}$ de alto por 26 de ancho, que llegan a $31 \mathrm{~cm}$ incluyendo la cresta, relacionándolo con el ejemplar de la ría de Huelva (Almagro Basch 1958: lám. 39). Sólo como casco cónico es valorado por

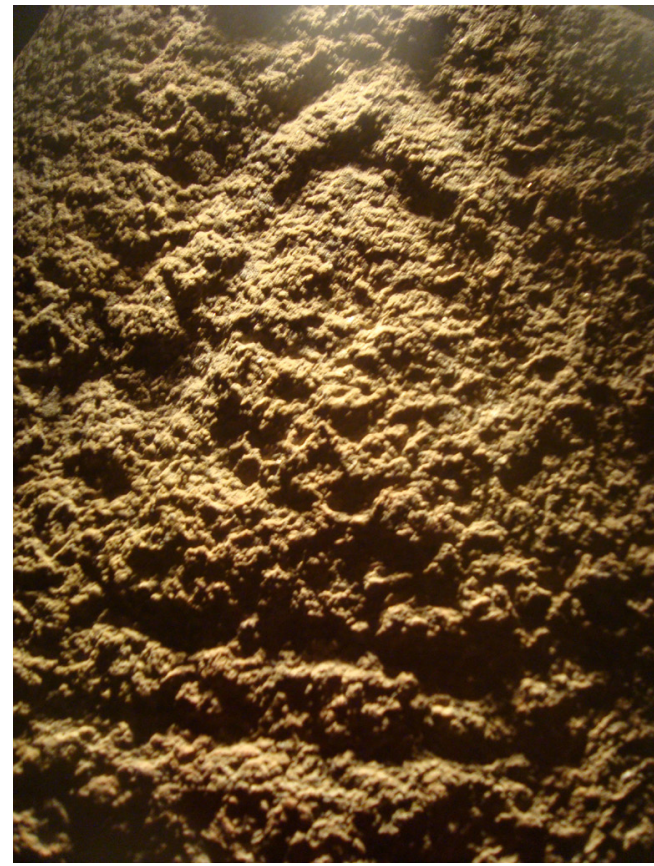

Marta Díaz Guardamino (2010: n 339), de cresta (Gomá 2018: 68), o más concretamente cónico apuntado con cresta de tipo Biebesheim (Mödlinger 2017: 92, 145 n. 716), donde el doble trazo sería una indicación de la protección orgánica dentro del casco, mientras es citado como de "doble cono" por Sebastián Celestino (2001: 343) el cual creemos que corresponde a la cresta. Por sus dimensiones, Juan Antonio Barceló (1989: 77) sugiere que podría ser una fíbula, ya que duda de la presencia de cascos.

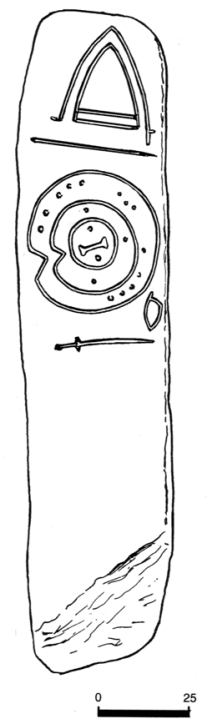

Figura 4.1a. Estela de Santa Ana de Trujillo (Cáceres) (Celestino 2001: 343 fig.).
Figura 4.1b. Casco de la estela de Santa Ana de Trujillo (Cáceres). Museo de Cáceres. Foto: A. Mederos. 


\subsection{Fundão}

Esta estela fue localizada en Qinta dos Gallegos, Telhado (Fundão, Castelo Branco, Beira Baixa) en mayo de 2012, a $450 \mathrm{msnm}$, durante la realización de la carta arqueológica del municipio. Presenta grandes dimensiones, $2.67 \mathrm{~m}$ de altura y $0.85 \mathrm{~m}$ de ancho, reaprovechando una roca granítica, quizás un antiguo menhir (Mendes y Bizarro 2015: 95). Se trata de una estela de composición tripartita que presenta un gran escudo con escotadura en $\mathrm{V}$ externa y con remaches en grupos de 3 y 2, una lanza en la parte superior y una espada por debajo del escudo. La espada tiene bordes paralelos y una empuñadura cuadra$\mathrm{da}$, y aunque no tiene indicados los remaches, creemos que podría tratarse de una espada de tipo Rosnöen. Entre la lanza y el escudo parece haber un espejo y una fíbula en posición sobre el hombro derecho, que se considera de arco multicurvilíneo por Raquel Vilaça et al. (e.p.), quienes también identifican un peine, aunque podría ser un colgante de la fíbula. El casco cónico apuntado presenta una cres- ta clara, como el de Santa Ana de Trujillo, y presenta en la parte inferior 4 remaches decorativos a ambos extremos.

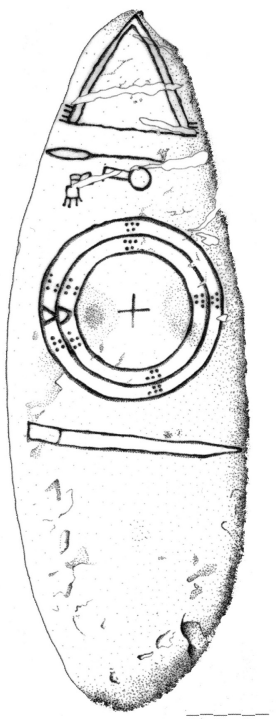

Figura 4.2a. Estela de Fundão (Castelo Branco, Beira Baixa, Portugal) (Mendes y Bizarro 2015: portada).

Figura 4.2b. Casco de la estela de Fundão (Beira Baixa). Museo Arqueológico Municipal. Foto: A. Mederos.

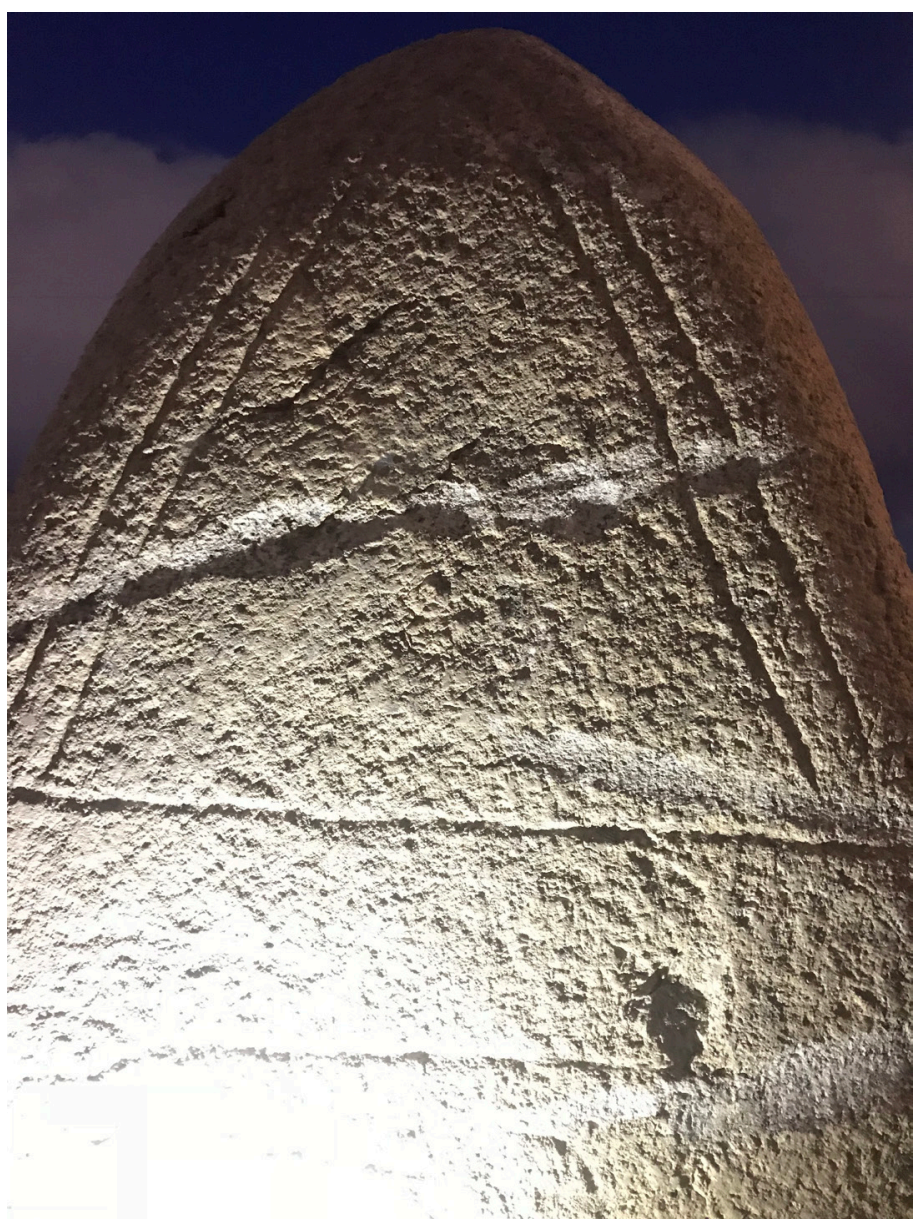




\subsection{Aldeia Velha, Sabugal}

Esta estela de Aldeia Velha (Sabugal, Guarda, Beira Alta), a $6 \mathrm{~km}$ de la frontera española, en la comarca de Alto Côa, fue identificada en 2008 en una vivienda, quizás procedente de las inmediaciones del poblado de Sabugal Velho. Aprovecha un soporte cuadrangular de $1.88 \mathrm{~m}$, del que sugieren Vilaça et al. (2011: 350) si se trataría de una estatua menhir. Presenta un gran escudo con escotadura en $\mathrm{V}$ al exterior, con lanza en la parte superior y espada en la inferior dentro de este soporte, pues la punta de la lanza y toda la espada se conservan. Es posible que tuviera en su parte superior un casco con cresta, partido en su parte superior, que ha sido modificado posteriormente añadiéndo- le una visera y un posible rostro (Vilaça et al. 2011: 348-349, 353, 363 fig. 1 y 2). Las dos líneas del casco sugieren la presencia de una cresta como se observa en los ejemplares de Santa Ana de Trujillo y Fundão. La espada, por sus pequeñas dimensiones, $0.28 \mathrm{~m}$, se plantea si sería un puñal o machete (Vilaça et al. 2011: 349, 351). Sin embargo, creemos que se adapta a las dimensiones del soporte y por su empuñadura rectangular, aunque carece de remaches en la empuñadura, no descartamos que fuese una espada de tipo Rosnöen. La presencia de un motivo no identificado bajo el casco, por encima de la lanza, debido a su ubicación creemos que pudo haber al menos un espejo, que habría sido modificado posteriormente como lo fue el casco.
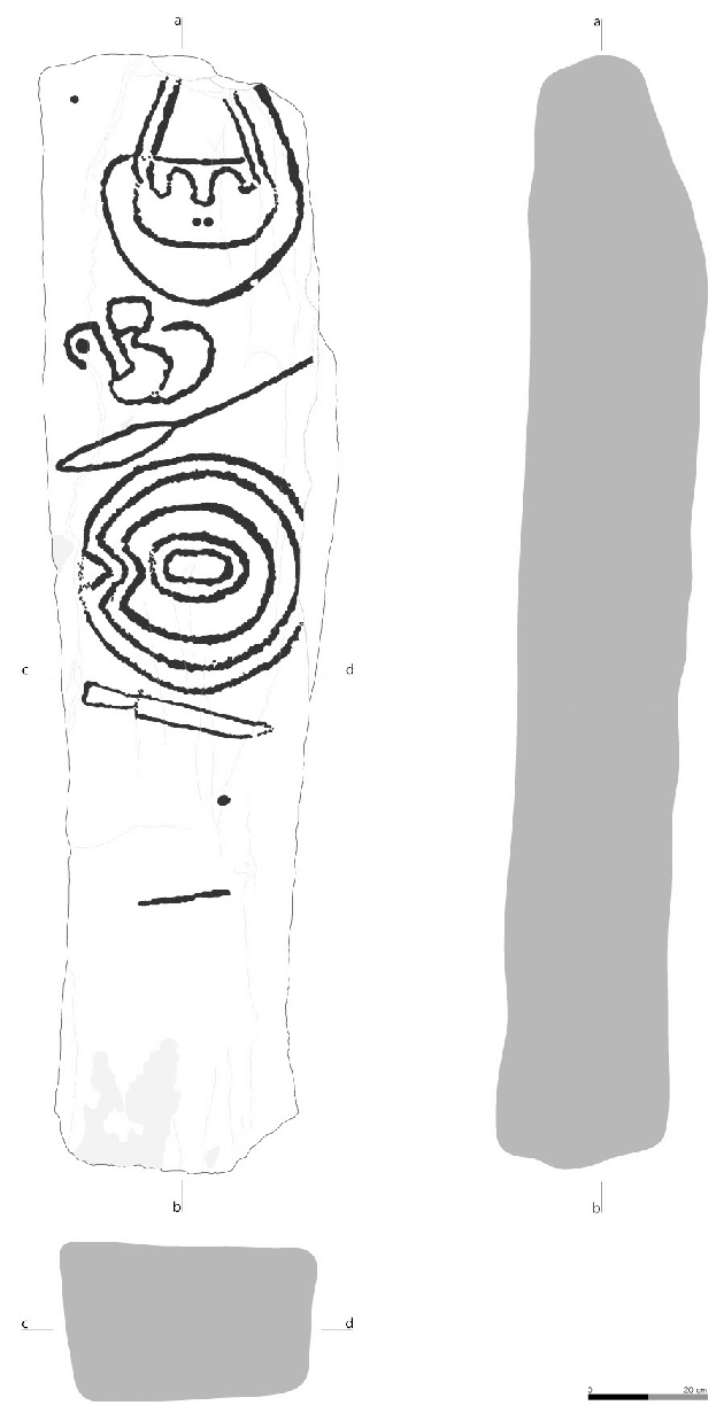

Figura 4.3a. Estela de Aldeia Velha (Sabugal, Guarda, Beira Alta, Portugal)

(Vilaça et al. 2011: 363 fig. 1). 
Figura 4.3b. Casco de la estela de Aldeia Velha (Beira Alta). Museo Municipal de Sabugal. Foto: A. Mederos.

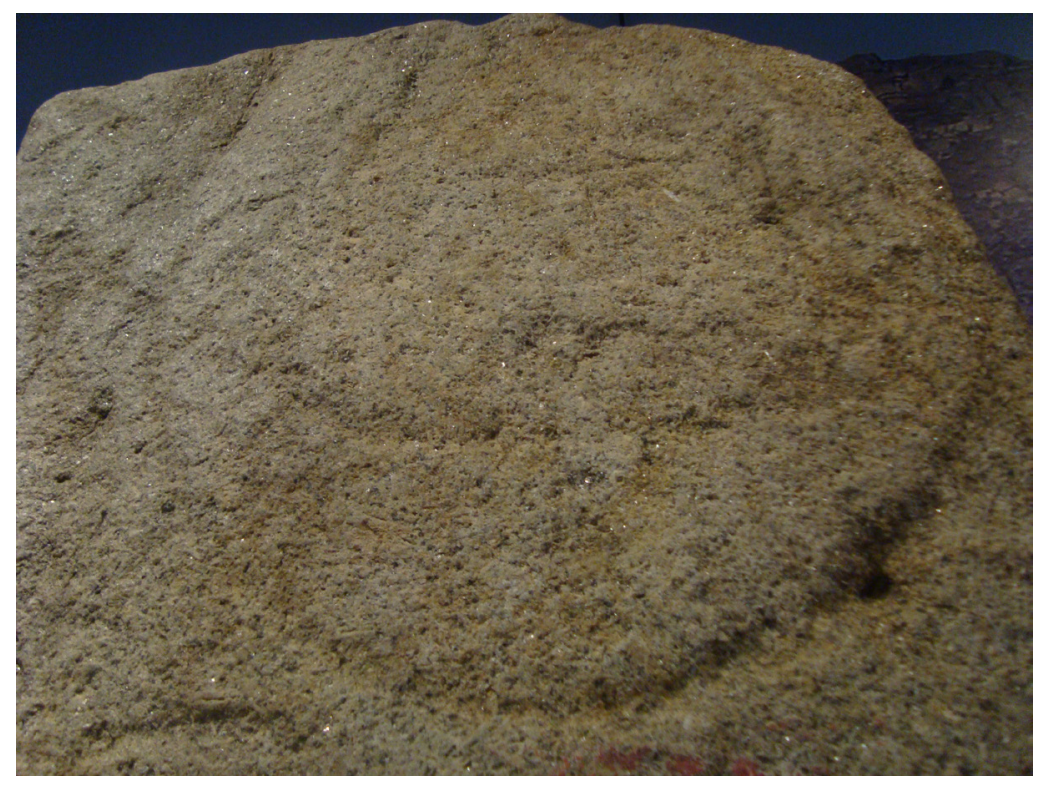

\subsection{Baracal II, Sabugal}

En una vivienda de Baracal (Sabugal, Guarda, Beira Alta) apareció una segunda estela de $1.90 \mathrm{~m}$ de altura y $0.64 \mathrm{~m}$ de ancho en mayo de 2006. Presenta un escudo con escotadura en $\mathrm{V}$ externa con lanza en la parte superior y espada de bordes paralelos y $0.53 \mathrm{~m}$ de largo en la parte inferior. La lanza está orientada hacia la derecha y la espada a la izquierda, esto es, a la inversa de lo que es habitual porque la escotadura está orientada hacia la derecha, que es la que marca la dirección de los elementos complementarios. Por debajo de la espada aparece un espejo con mango que presenta dos elementos redondeados que deben ser decorativos, bien con forma redonda para facilitar el agarre con el puño o más probablemente con sección plana (Santos, Vilaça y Marques 2011: 324-325, 339 fig. 3, 341 fig. 7). Un quinto motivo no identificado en la parte superior de la estela (Santos, Vilaça y Marques 2011: 324, 328), a pesar de estar bastante fragmentado, creemos que correspondería a la parte inferior de un casco que presenta un remache lateral en el dibujo y quizás haya un segundo remache según la foto.

Figura 4.4a. Estela de Baracal II (Sabugal, Guarda, Beira Alta, Portugal) (Santos et al. 2011: 339 fig. 3).
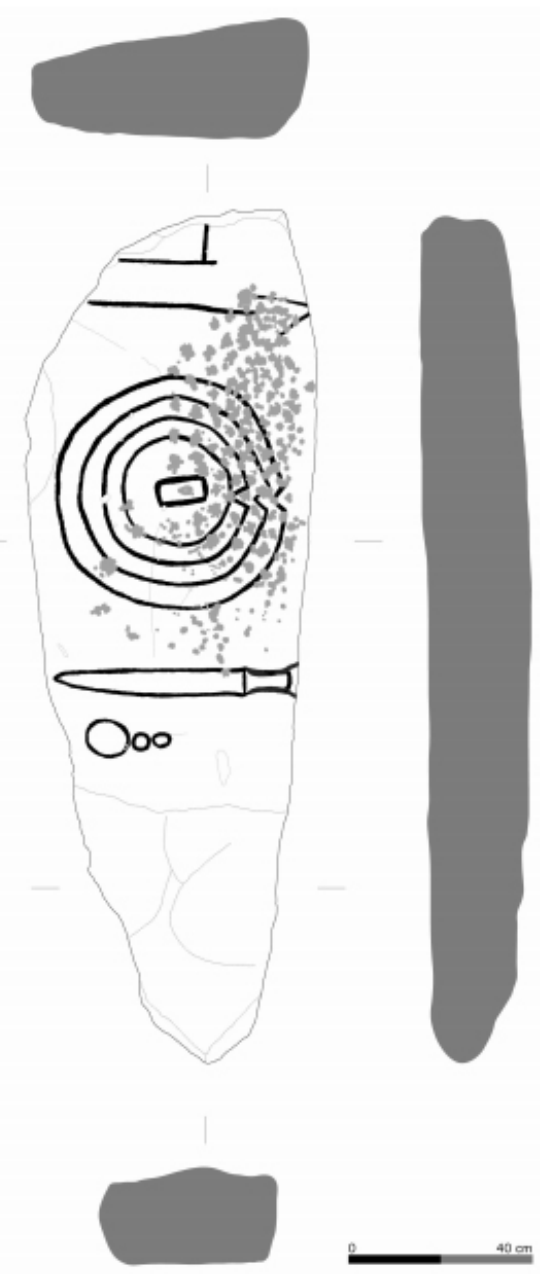

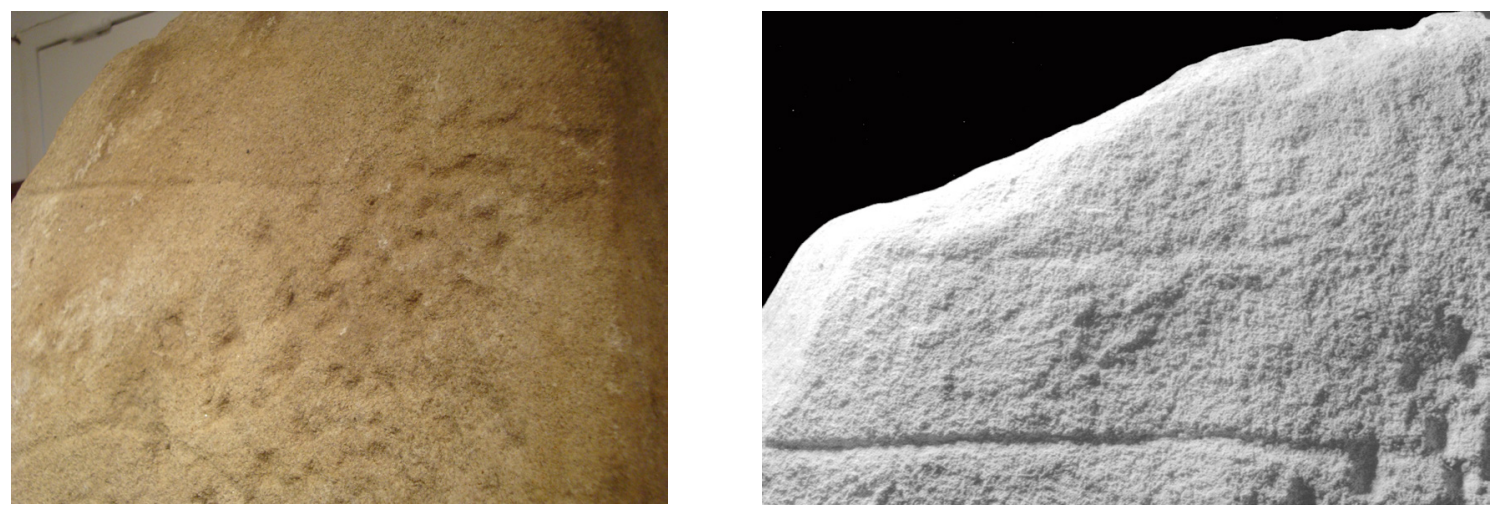

Figura 4.4b y 4.4c. Casco de la estela de Baracal II (Beira Alta). Museo Municipal de Sabugal. Foto: A. Mederos y Santos et al. 2011: 340 fig. 4.

\subsection{Zebros, Idanha-a-Nova}

La estela de Zebros (Zebreira, Idanha-a-Nova, Castelo Branco, Beira Baixa) fue localizada en 2011 en un llano agrícola a $250 \mathrm{msnm}$. Se encontraba fragmentada, con unas dimensiones máximas de $0.50 \mathrm{~m}$ de altura, $0.30 \mathrm{~m}$ de ancho y $0.24 \mathrm{~m}$ de grosor. Presenta un escudo con escotadura en $\mathrm{V}$ exterior, con lanza en la parte superior y espada en la inferior, partidas en su lado derecho. La espada también es de pequeñas dimensiones, $0.28 \mathrm{~m}$, y les hace dudar si se trata de un puñal (Henriques, Lobato y
Caninas 2012: 31-36, 32 fig. 5 y 7), pero creemos que se debe a que se ajusta al ancho de la estela. Por otra parte, su mango rectangular, también sin remaches, sugiere que podría tratarse de una espada Rosnöen. El posible casco de Zebros está muy fragmentado, por lo que lo creen dudoso, pero dada su posición por encima de la lanza es la mejor opción. No se indica con un doble trazo ni una posible cresta, ni la presencia de remaches decorativos pero puede deberse a su conservación parcial, pudiendo tener una cresta más pequeña en la parte superior como sucede con los cascos de tipo Mantes.

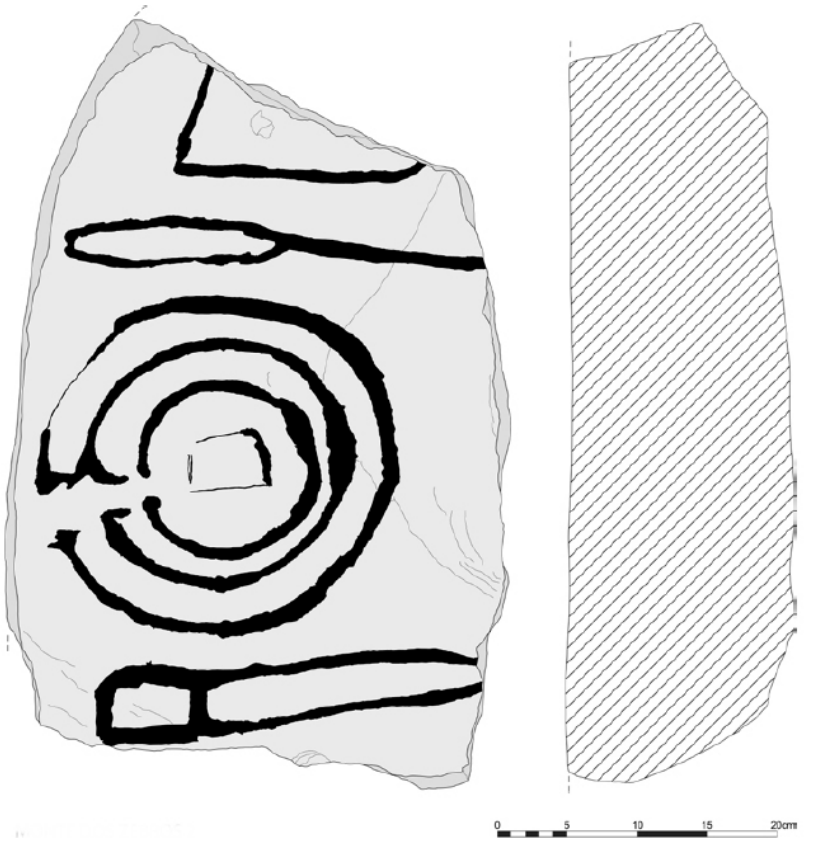

Figura 4.5a. Estela de Zebros (Idanha-a-Nova, Castelo Branco, Beira Baixa, Portugal) (Henriques et al. 2012: 32 fig. 7). 


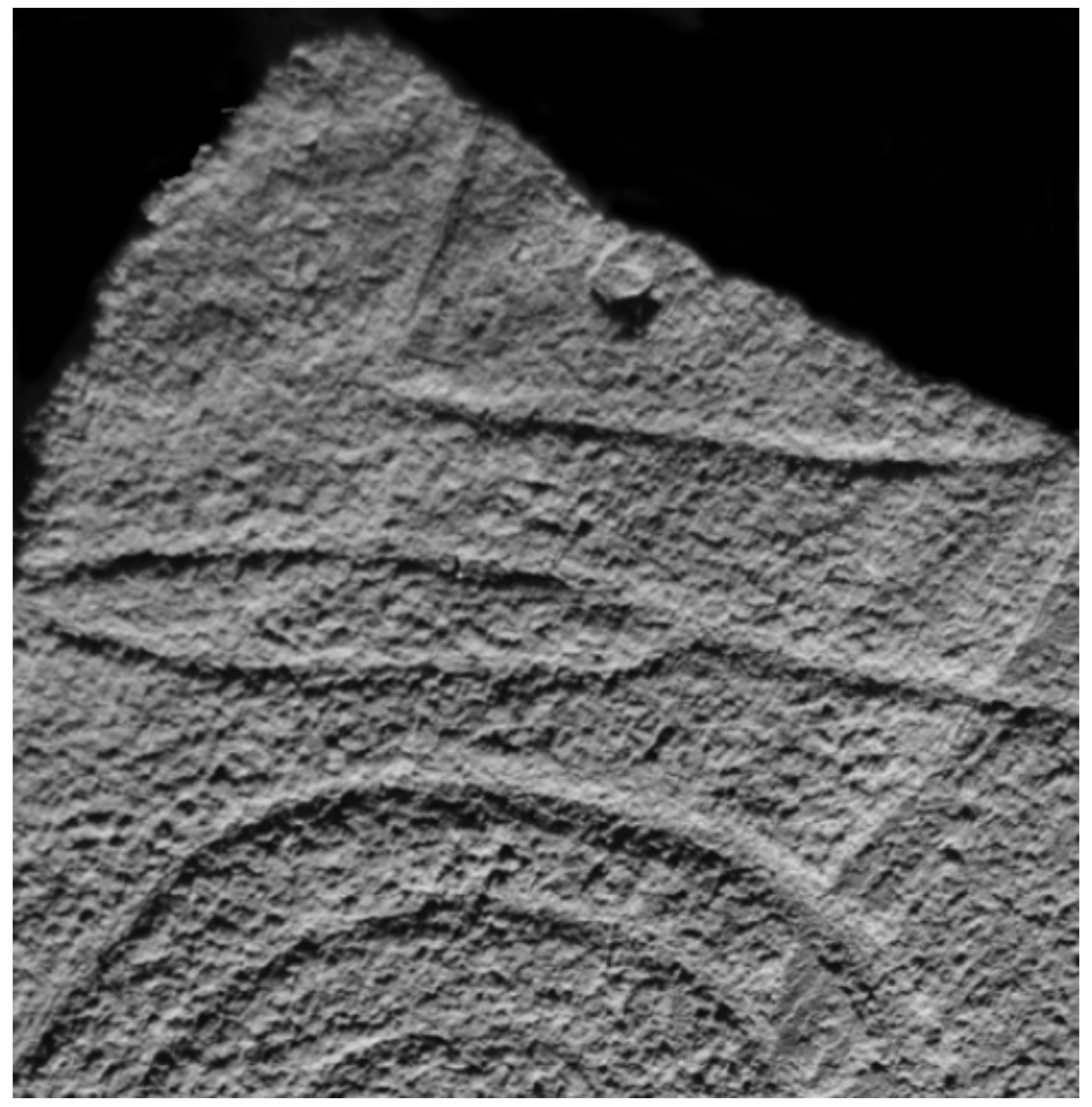

Figura 4.5b. Casco de la estela de Zebros (Beira Baixa) (Henriques et al. 2012: 32 fig. 5).

\section{Estelas fragmentadas que pudieron tener casco cónico con cresta}

\subsection{Pedra da Atalaia I}

La estela de Pedra da Atalaia I (Celorico de Beira, Guarda, Beira Alta), fragmentada en su parte superior, fue localizada durante un seguimiento preventivo por la construcción de un parque eólico en 2005. Conserva unas medidas de 1.38 $\mathrm{m}$ de longitud por $0.60 \mathrm{~m}$ de ancho y $0.22 \mathrm{~m}$ de grosor. Presenta el escudo central con escotadura en $\mathrm{V}$ exterior y una espada de $0.43 \mathrm{~m}$ en la parte inferior, pero no se conserva la lanza y si hubo un posible casco. No obstante, por debajo de la espada presenta también un espejo (Vilaça et al. 2011: 299-300, 316 fig. 4-5). La espada se ha sugerido que sería de tipo pistiliforme, pero creemos que es de bordes paralelos, pues no se observa engrosamiento en la hoja.

Figura 4.6. Estela de Pedra da Atalaia I (Celorico de Beira, Guarda, Beira Alta)

(Vilaça et al. 2011: 316 fig. 4).

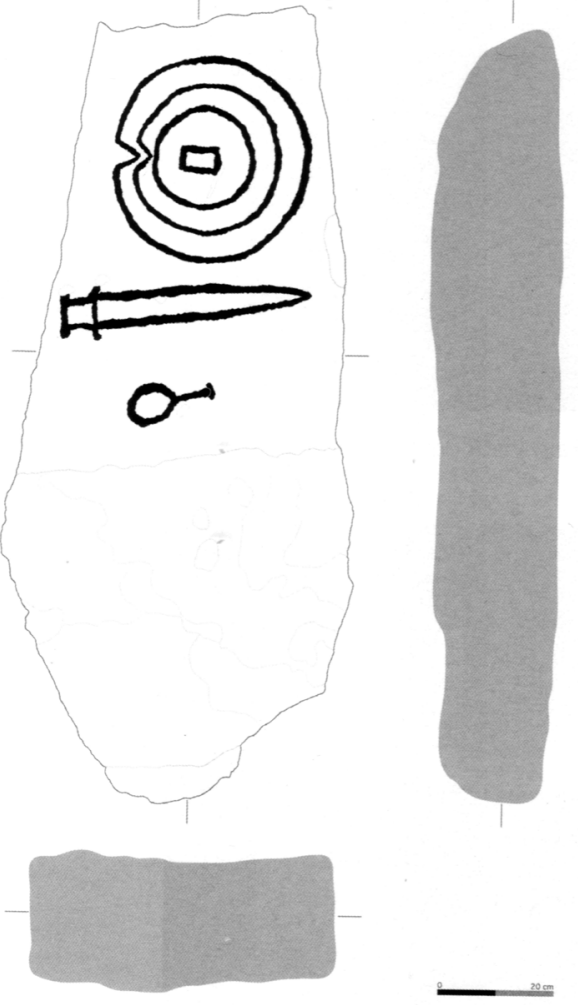




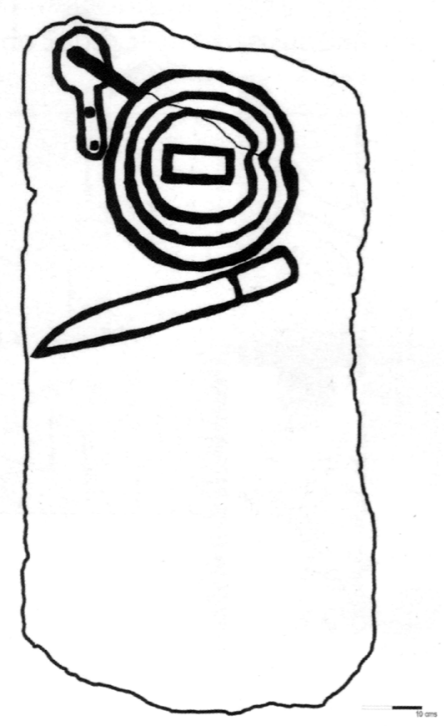

Figura 4.7. Estela de Cabezuela del Valle (Cáceres) (Sanabria 2011: 386 fig. 3).

\subsection{Cabezuela del Valle}

La estela localizada a $800 \mathrm{~m}$ del Puerto de Honduras (Cabezuela del Valle, Cáceres), procedente de la Sierra de la Cabrera, cuenta con unas dimensiones máximas conservadas de $1.24 \mathrm{~m}$ de altura por $0.62 \mathrm{~m}$ de ancho, 0.15 $\mathrm{m}$ de grosor y se incorporó en 2008 al Museo de Cáceres después de su descubrimiento fortuito. Presenta un escudo con escotadura en $\mathrm{V}$ externa y debajo una espada de $0.44 \mathrm{~m}$, no conservándose la lanza en la parte superior, aunque sí un espejo que presenta dos calados en el mango (Sanabria 2011: 371, 374-376, 386 fig. 3). Se plantea la hipótesis que al fragmentarse la estela se regrabó sobre el escudo la lanza aprovechando una grieta natural (Sanabria 2011: 376, 387 fig. 5), idea que no compartimos. La espada con bordes paralelos presenta una empuñadura rectangular que podría estar indicándonos una espada de tipo Rosnöen, mientras que posible el casco tampoco se conserva.

\subsection{Alburquerque}

La estela de Tres Arroyos (Alburquerque, Badajoz) fue una de las primeras en ser identificadas (Cabré 1923: 54-55 fig. 8), pero lamentablemente desapareció durante la Guerra Civil del Museo Arqueológico de Badajoz. Presentaba roturas en la parte superior, la base y su lado izquierdo. Con una iconografía de escudo con escotadura en V externa, lanza en la parte superior cuya punta no se conserva y espada por debajo del escudo, también fragmentada en el arranque de la empuñadura. Encima de la lanza se grabó un espejo (Almagro Basch 1966: 61, fig. 18). Presenta una espada con empuñadura rectangular, sin remaches, que podría ser de tipo Rosnöen, pero es considerada por Juan Cabré (1923: 55) "un sable o machete, y de un solo filo". La fractura en el extremo superior apuntado de la estela, que se marca bien en el dibujo publicado por Cabré (1923: 54 fig. 8), impide saber si presentaba también un casco, dibujo que además no realizó directamente, sino a partir de "una fotografía muy pequeña".

Figura 4.8. Estela de Alburquerque (Badajoz). Desaparecida, croquis sobre foto de Cabré (1923: 54 fig. 8).

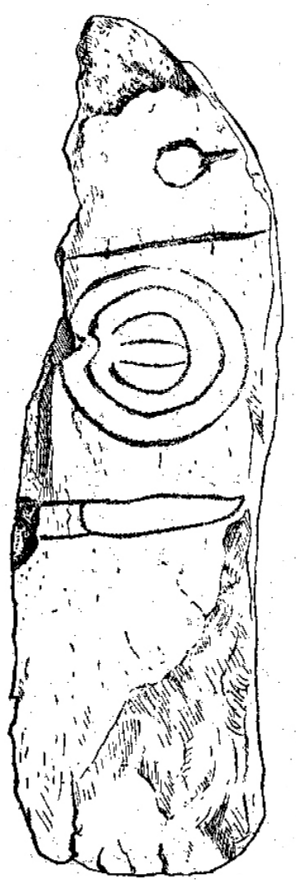

5. Estelas con escudo central y antropomorfo por debajo, con espada pistiliforme cerca de la mano, que presentan cascos cónicos apuntados con cresta

\subsection{Cabañas del Castillo}

Esta estela de Cabañas del Castillo (Cáceres), de $1.24 \mathrm{~m}$ de altura y $0.48 \mathrm{~m}$ de ancho, la más recientemente publicada, fue identificada en 2004 cuando se trasladó de una pedrera del municipio de Cabañas del Castillo a una portada de una finca y más tarde a una vivienda particular en Trujillo (Cáceres). Presenta un gran escudo con escotadura en $\mathrm{V}$ al exterior y remaches en gru- 
pos de 3, con una lanza en la parte superior, rota en sus extremos, pero ya no se representa en posición la espada de tendencia pistiliforme, pues aunque está por debajo del escudo, se encuentra desplazada hacia un lateral por la presencia de un posible antropomorfo bastante fragmentado (Rodríguez y González Bornay 2018: 1458, 1460, 1466, 1463 fig. 8, 1461 fig. 6). Por debajo del escudo aparece un espejo como sucede en la estela de Santa Ana de Trujillo y una fíbula de codo asimétrico descentrado. El casco cónico apuntado presenta cresta, aunque está fragmentado en la parte superior, y cuenta con un diámetro de 20 $\mathrm{cm}$, con dos remaches en cada extremo.

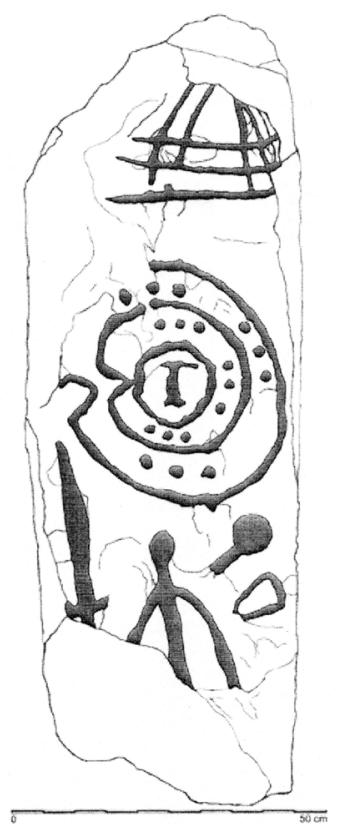

Figura 5.1. Estela de Cabañas del Castillo (Cáceres) (Rodríguez y González Bornay 2018: 1463 fig. 8). Colección particular (Cáceres).

\subsection{Cabeza de Buey I}

En la finca La Baileja se localizó en 1940 la estela de Cabeza de Buey I (Badajoz) (32) (Ramón y Fernández Oxea 1950: 298-299, 301 fig. 11, fig. 23; Almagro Basch 1966: 69-71, fig. 21, lám. 16), fragmentada en la parte inferior, de $1.12 \mathrm{~m}$ de altura y $0.85 \mathrm{~m}$ de ancho. Presenta un escudo con escotadura en $\mathrm{V}$ externa con remaches en su interior y un antropomorfo de tamaño similar, con una lanza por encima del escudo. La representación del casco es atípica porque el casco no está individualizado, separado del cuerpo, sino situado dentro de la cabeza y se ha sugerido que puede tratarse de un casco sin cresta (Galán 1993: 103 n 44). La cabeza se introduce dentro del casco, como sucede también en Setefilla, y se marca con un doble surco ancho. La razón del doble surco creemos que es para indicar que trata de un casco cónico apuntado con cresta por la separación de la cabeza de la parte más alta del casco. En caso de no haber tenido cresta hubiera bastado con un único trazo. No obstante, se ha sugerido por Marianne Mödlinger (2017: 92) que podría ser un casco hemiesférico de cuero o un casco metálico pero indicándose la protección interior orgánica para la cabeza. Por otra parte, Sebastián Celestino (2001: 151, 153, 362-363 fig.) y Richard Harrison (2004: 235) dudan si es un casco cónico, una diadema o un tocado, que se ha simplificado por la falta de espacio ante la proximidad del escudo. Los dos puntos a ambos lados de la cabeza, que no recoge en su dibujo Almagro Basch, pero sí Celestino y Harrison, podría pensarse que son unos pendientes como sugieren Celestino (2001: 363) y Díaz Guardamino (2010: $n^{\circ} 262$ ), pero de ser un casco podrían ser también parte de un cierre orgánico del casco como sucede en Ategua. En la estela todavía se trata de representar la espada por debajo del escudo y por eso el antropomorfo también se sitúa por debajo del escudo con la espada junto a la mano derecha, como igualmente sucede en $\mathrm{Ca}-$ bañas del Castillo. La espada es pistiliforme por el ensanche en la parte final de la hoja (Fig. 5.2).

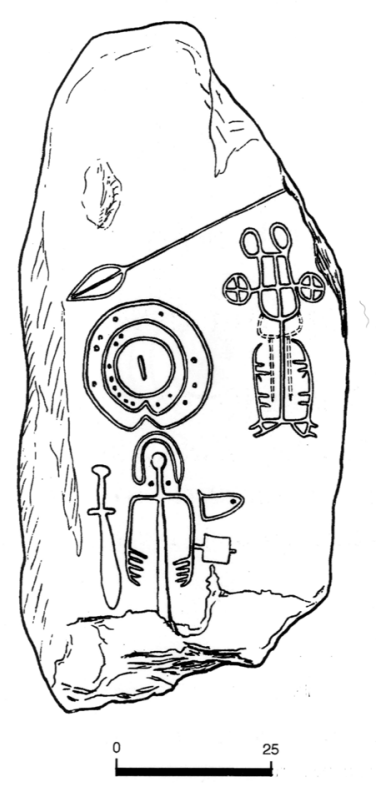

Figura 5.2. Estela de Cabeza de Buey I (Badajoz) (Almagro Basch 1966: 70 fig. 21). Colección particular (Badajoz). 


\subsection{Valencia de Alcántara III}

Otro posible casco ha sido el propuesto para la estela fragmentada de Valencia de Alcántara III (Cáceres) (12) (Almagro Basch 1966: 114115, fig. 38, lám. 33), con $0.93 \mathrm{~m}$ de altura $\mathrm{y}$ 0.40 de ancho máximo conservados, aparentemente sin representación humana. Se trata de una estela anómala porque representa objetos de gran tamaño y carece de escudo, que presumiblemente debía encontrarse por encima de la espada, como sucede en Valencia de Alcántara I y II. Buena parte de los autores desde Almagro Basch (1966: 114 fig. 38) han considerado la mitad conservada como un casco cónico apuntado con dos remaches (Díaz Guardamino 2010: $n^{\circ} 352$ ), con cresta y remaches (Almagro Gorbea 1977: 169, 181; Harrison 2004: 205; Gomá 2018: 68), o concretamente cónico con cresta de tipo Biebesheim (Mödlinger 2017: 145 n. 716), aunque la cresta no aparece indicada con un segundo trazo. Como fíbula de arco con un resorte es identificado el objeto inferior por Celestino (2001: 337) y su gran tamaño es interpretado como resultado del valor y del prestigio que aportaban estos objetos (Celestino 2001: 195). Aunque la posible fíbula está partida en un extremo, como toda la estela, la presencia del resorte en el extremo izquierdo podría apoyar esta identificación. No obstante, las otras dos estelas de Valencia de Alcántara presentaban un carro en su parte inferior y creemos viendo la foto que quizás el medio casco sea un équido y la denominada fíbula corresponda a la caja de un carro. Esto daría más lógica a esta estela de la que sólo se ha publicado la foto de Almagro Basch (1966: lám. 33), en la cual el supuesto casco en vez de estar en la parte superior se encontraría por debajo de la espada, algo que iconográficamente no se repite en ningún otro caso. Según nuestra propuesta, por encima de la espada al menos se habría perdido un escudo con escotadura en $\mathrm{V}$ y la lanza.

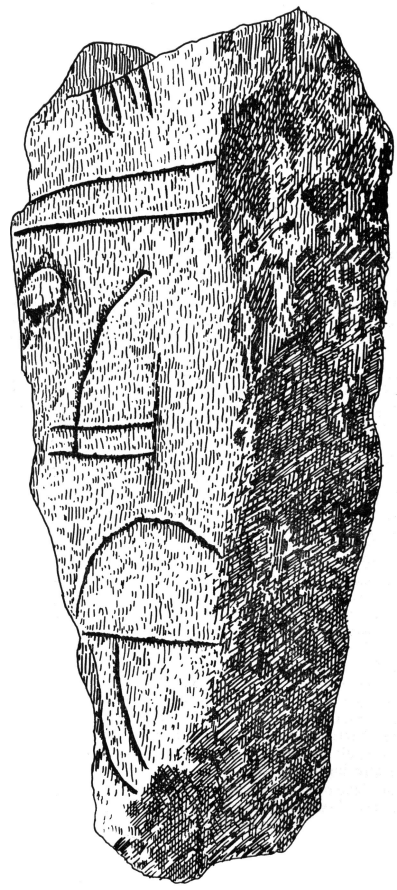

6. Estelas con escudo y antropomorfo, de similar importancia, que presentan cascos cónicos apuntados con posible cresta

\subsection{Zarza de Montánchez}

La estela de Zarza de Montánchez (Badajoz) (21), dada a conocer por primera vez brevemente por Alfonso Naharro (1976: 28), indica la continuidad de los cascos en estelas donde el escudo y un antropomorfo tienen la misma importancia, mientras se ha alterado la composición previa al ponerse una espada junto a la lanza, por encima de un escudo que ya sólo presenta la escotadura en $\mathrm{V}$ al interior. El casco se ha publicado con 3 remaches y forma redondeada (Almagro Gorbea 1977: 181, 171 fig. 68/2; Almagro Gorbea y Sánchez Abal 
1978: 418-420, fig. 1), que en el posterior dibujo presentado por Celestino (2001: $347 \mathrm{fig}$. cat. 21; Harrison 2004: 217-218) es mucho más apuntado y con sólo dos remaches, siendo considerado un casco cónico apuntado con cresta de tipo Biebesheim (Mödlinger 2017:
145 n. 716). Por otro lado, Barceló (1989: 77) duda que sea un casco y por su asociación con la espada y la lanza sugiere que podría ser una fíbula, dudas que también manifiesta Gomá (2018: 68), aunque sí acepta que es un posible casco.
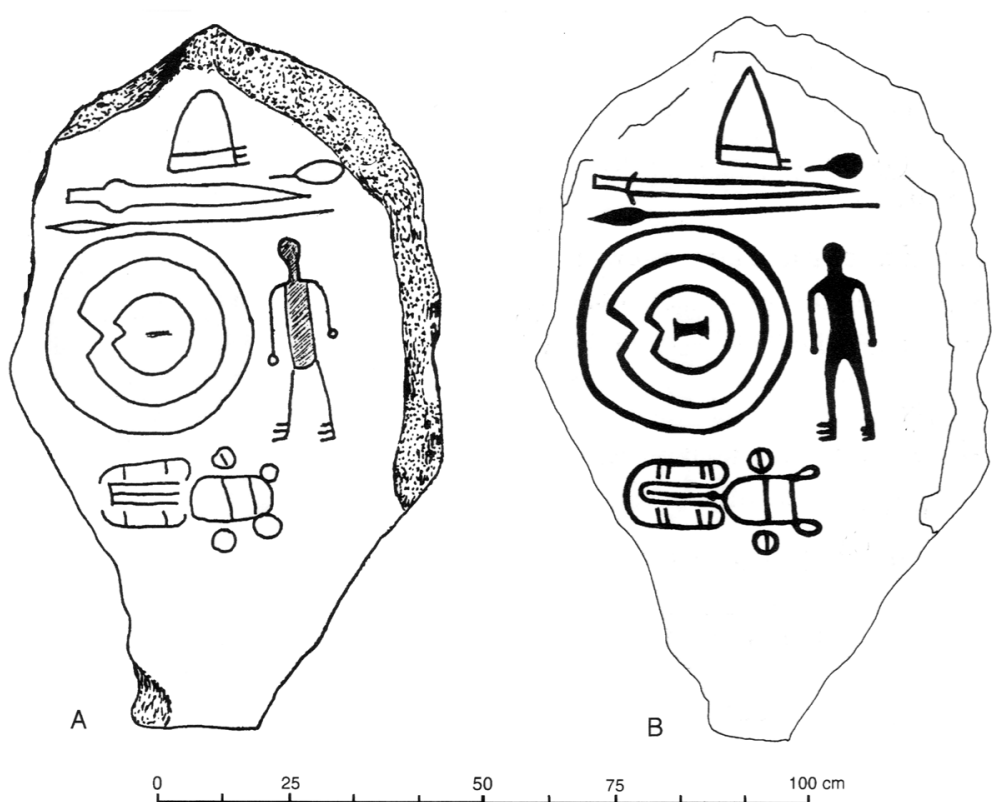

Figura 6.1a. Estela de Zarza de Montánchez (Badajoz) con dos representaciones del casco según Almagro Gorbea y Celestino (Harrison 2004: 217-218 n²1).

Figura 6.1b. Casco de la estela de Zarza de Montánchez (Badajoz). Museo de Cáceres. Foto: A. Mederos.

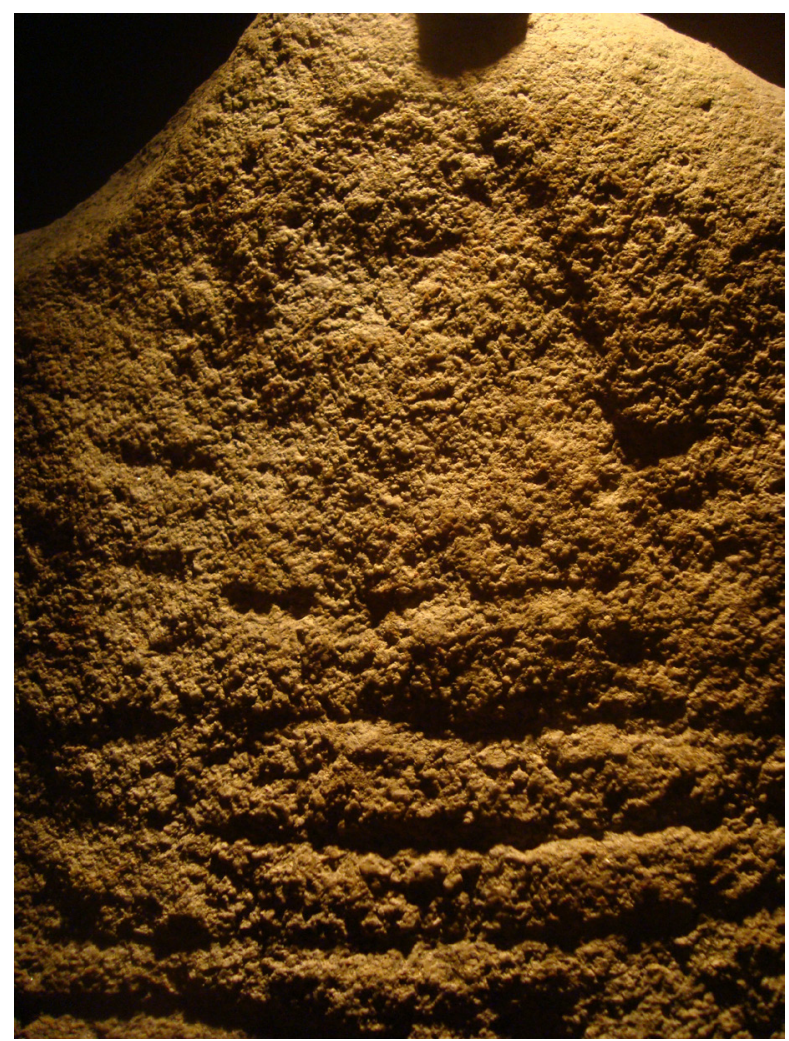




\subsection{Las Herencias I}

La estela de Barro Seco (Las Herencias, Toledo) (25), localizada al arar, permaneció en un linde hasta su conocimiento en 1980 por el Museo de Santa Cruz de Toledo (Anónimo 1982: 88, fig. 7; Chapa y Pereira 2016: 358). Fragmentada en su extremo superior derecho, conserva unas dimensiones de $0.75 \mathrm{~m}$ de altura y $0.42 \mathrm{~m}$ de ancho máximo. Presenta una figura humana, ya con la misma importancia que el escudo, el cual tiene una escotadura en $\mathrm{V}$ al interior (Fernández-Miranda 1986: 464). Los otros elementos se articulan en función del antropomorfo, como una fíbula, una lanza junto a su brazo derecho y un carro a sus pies, estando ausente la espada. Celestino (2001: 353) cree ver un punto junto al hombro derecho, que interpreta como brazalete, aunque normalmente es la zona de la fíbula, pero quizás no había espacio suficiente para grabarla por la proxi- midad de la lanza. Junto a la mano izquierda, Manuel Fernández Miranda (1986: 467) sugiere con dudas unas tenazas. Sobre la cabeza hay dos trazos triangulares muy esquemáticos que sugieren un casco cónico apuntado que Fernández Miranda (1986: 464, 466) interpreta como un casco apuntado con cimera o cresta (Galán 1993: 99; Harrison 2004: 223), concretamente cónico con cresta de tipo Biebesheim (Mödlinger 2017: 145 n. 716), aunque no está representada la cresta con un doble trazo. Es posible que este hecho haya llevado a Gomá (2018: 68) a interpretarlo como un casco cónico apuntado oriental sin cresta. La ausencia de la espada es explicada por Harrison (2004: 223-224) en función dos episodios en la elaboración de la estela, uno inicial con espada pistiliforme, escudo y carro, que luego se modificó utilizando la espada para trazar el antropomorfo con casco, añadiéndose la lanza y una fíbula por su trazado más fino.

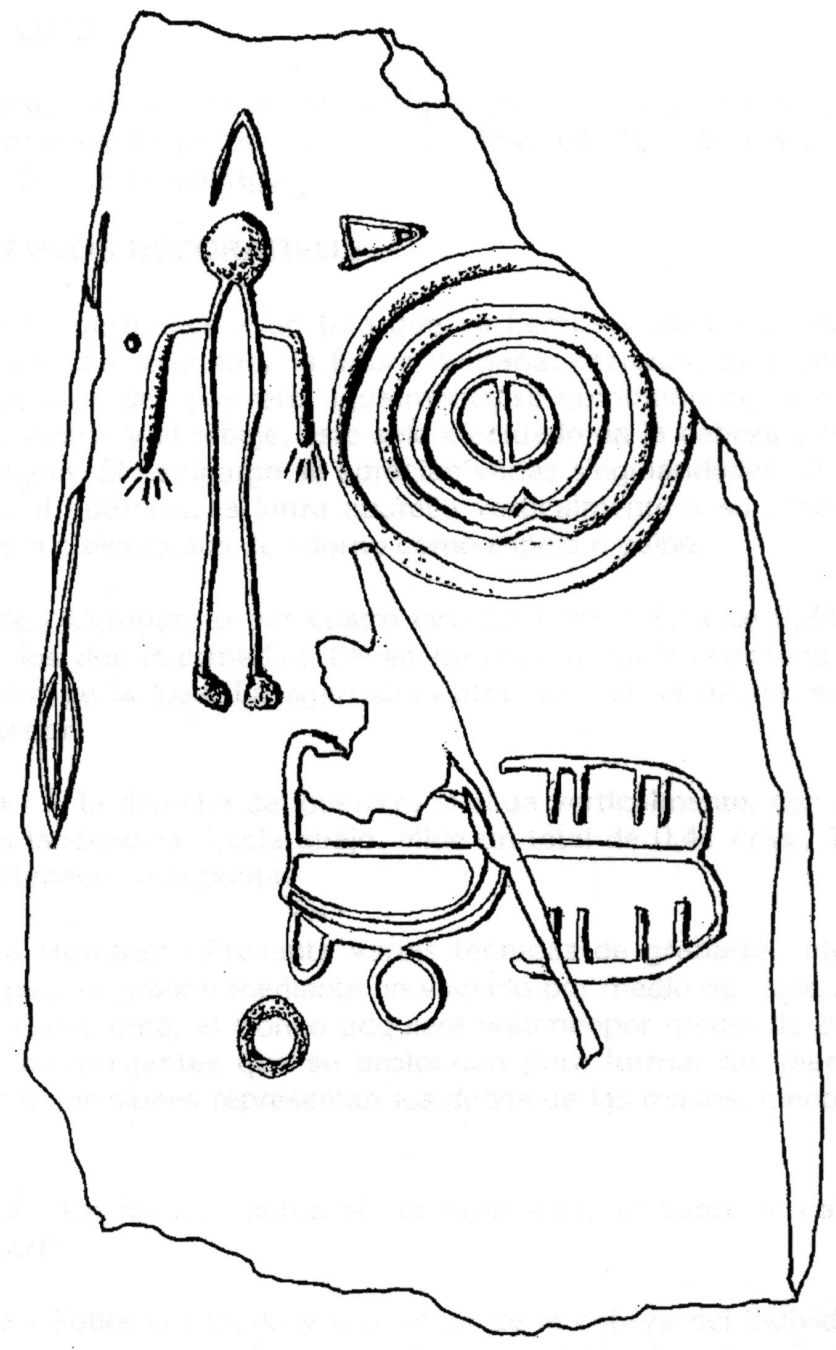

Figura 6.2a. Estela de Las Herencias I (Toledo) (Celestino 2001: 352 fig.). 
Figura 6.2b. Casco de la estela de Las Herencias I (Toledo). Museo de Santa Cruz de Toledo. Foto: A. Mederos.

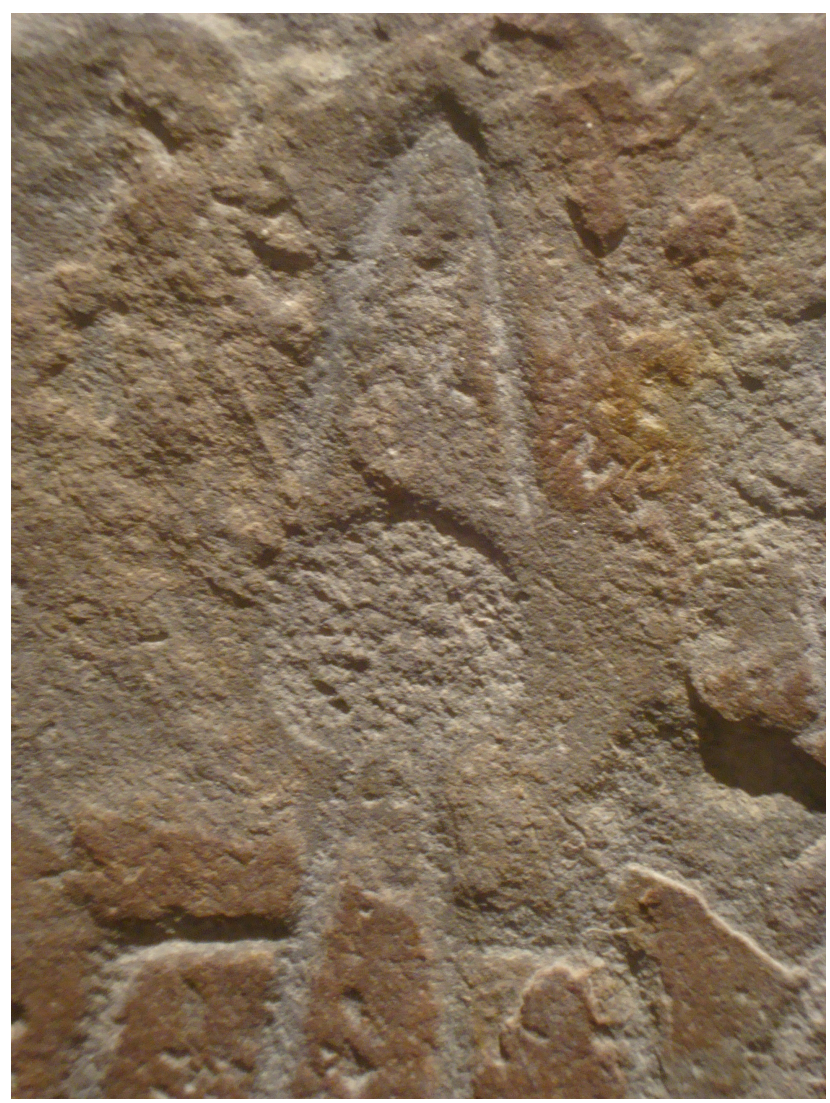

\subsection{Almargen}

La estela de Almargen (Málaga) (84) fue localizada cerca del casco urbano, junto a un camino. Presenta unas dimensiones de $1 \mathrm{~m}$ de altura y $0.60 \mathrm{~m}$ de ancho (Villaseca 1993: 218-219, 225 lám. 2). Se trata de una estela donde el antropomorfo está situado en un lateral y a un mismo nivel que el escudo con escotadura en $\mathrm{V}$ al exterior. En la parte superior figura una lanza y en la parte inferior debería haber una espada que no se representó salvo que estuviera cerca de la mano derecha y se perdiera al fragmentarse el lateral, además de una fíbula de codo asimétrico descentrado a la altura del hombro derecho. En las monografías de Celestino (2001: 438) y Díaz-Guardamino (2010: $n^{\circ} 248$ ) el dibujo aparece invertido. Sobre la cabeza hay dos trazos muy esquemáticos que convergen y sugieren un casco cónico apuntado, el cual debería tener cresta pero no está representada. No obstante, se ha sugerido un casco cónico apuntado con cresta cóncava triangular de tipo Bernières d'Ailly (Mödlinger 2017: 145 n. 718), mientras Gomá (2018: 68 ) opta por interpretarlo como un casco cónico apuntado oriental sin cresta

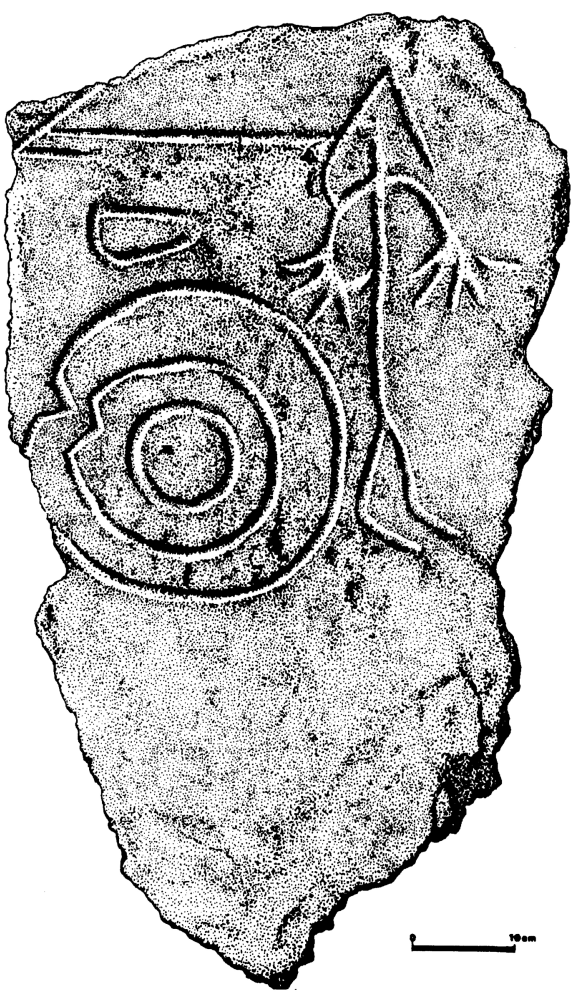

Figura 6.3a. Estela de Almargen (Málaga) (Villaseca 1993: 225 lám. 2). 


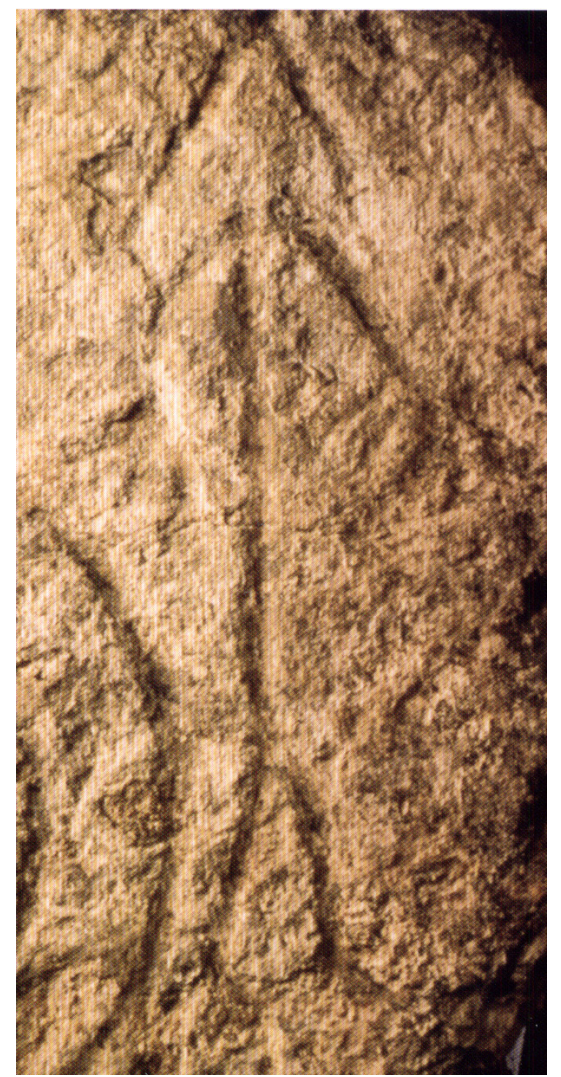

Figura 6.3b. Casco de la estela de Almargen (Málaga). Museo Municipal de Almargen.

\section{Estelas con antropomorfo en posición central que presentan cascos cónicos apuntados con cresta cóncava}

\subsection{Setefilla}

Esta estela apareció reutilizada sobre una fosa de inhumación, con un esqueleto orientado en dirección N-S, acompañado por restos de al menos una urna y huesos cremados, al pie de la Mesa de Setefilla (Lora del Río, Sevilla) (71), entre los túmulos I y G (Bonsor y Thouvenot 1928: 32, 35), con $1.70 \mathrm{~m}$ de altura y $0.45 \mathrm{~m}$ de ancho. Pasó en fecha indeterminada a una zona verde en la piscina municipal de Lora del Río donde fue localizada por María Eugenia Aubet (1997: 166, 165 lam. 1) cuando excavaba en Setefilla, siendo trasladada al Museo Arqueológico de Sevilla. La estela presenta un casco cónico apuntado con cresta cóncava triangular $\mathrm{y}$ un escudo sin escotadura en $\mathrm{V}$, indicativo que es un ejemplar tardío. Parece haberse grabado posteriormente un antropomorfo cuya cabeza se introduce dentro del casco. Este elemento ya fue identificado por George Bonsor y Raymond Thouvenot (1928: 32, 35, fig. 25), pero es considerado dudoso por Eduardo Galán (1993: 50). Volvió a ser publicado por Almagro Basch (1970: 327, 329 fig. 4, lám. 4), quien asocia el casco al de tipo Huelva, concretamente uno cónico apuntado con cresta cóncava triangular de tipo Bernières d'Ailly (Mödlinger 2017: 145 n. 718), aunque también se le considera de tipo cónico apuntado oriental sin cresta (Gomá 2018: 68).

Martín Almagro Basch relaciona la línea horizontal bajo el casco como una lanza o espada y la línea inferior como una espada, aunque en un trabajo posterior duda y atribuye la de arriba a una lanza o espada (Almagro Basch 1974a: 20, 18 fig. 5, 19 fig. 6). La estela volvió a ser interpretada por Manuel Bendala (1977: 196-197) como un posible portador de un lingote de cobre con forma de piel de toro, al que atribuye las líneas horizontales de los hombros y de la cintura. Sin embargo, Galán (1993: 108) y Celestino (2001: $418 \mathrm{n}^{\circ}$ 71) volvieron a considerar la línea inferior del lingote como una espada al cinto con empuñadura y la línea superior, aunque no la dibuja, como una posible lanza, dibujo que parece seguir Díaz-Guardamino (2010: $\mathrm{n}^{\circ} 340$ ) incorporando la espada y eliminando la línea horizontal sobre los hombros de la supuesta lanza. Posteriormente, Harrison (2004: 286) volvió a asignar la línea horizontal superior, que sí representa, a una lanza y la línea horizontal inferior a una espada al cinto, que es confirmada también en la última revisión de la pieza por Díaz-Guardamino (et al. 2015: 46-47, 53, 44 fig. 3, 49 fig. 10), aunque no se pronuncia por la línea horizontal sobre los hombros porque también cree observar una dudosa punta de lanza en un lateral, además con la punta hacia arriba que es más excepcional. Nuestra propuesta es que el casco, cónico apuntado con cresta cóncava triangular por los dos trazos a cada lado, tiene una línea horizontal inferior y es la siempre mencionada línea horizontal sobre los hombros, como sucede en tres ejemplos claros, Santa Ana de Trujillo, Cabañas del Castillo o Fundão, lo que implica que la figura humana se representó después que el casco, pero por la falta de espacio entre el casco y el escudo, se grabó la cabeza dentro del casco. 


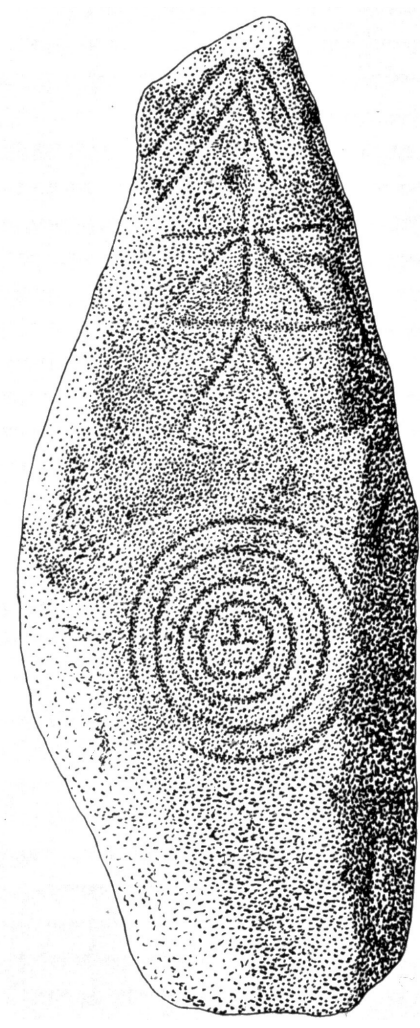

Figura 7.1a. Estela de Setefilla (Lora del Río, Sevilla)

(Almagro Basch 1970: 329 fig. 4).

\subsection{Ategua}

La estela de Ategua (Córdoba) (80) fue publicada inicialmente por Juan Bernier (1968 y 1968-69: 183, 182 fig. 1 y fot. 1), sólo con la foto y un croquis. La pieza fue presentada más en detalle casi simultáneamente en dos congresos durante 1968. En el primero se va a defender la hipótesis funeraria de la estela asociando el carro a un cortejo fúnebre durante el cual las 7 figuras inferiores estarían realizando una danza fúnebre en homenaje al muerto (Blanco, Luzón y Ruiz Mata 1969: 160-161, lám. 14-15). En el segundo congreso se presentó otra interpretación dividiéndola en tres zonas, indicando que en el segundo sector, bajo el gran antropomorfo, el individuo tendido sería un vencido y el de a pie un sirviente, o en una segunda publicación quizás su esposa, En la zona inferior indica que había un auriga conductor del carro de guerra de su señor y 7 figuras infantiles que considera los hijos del difunto (Almagro Basch 1970: 318-322, 320 fig. 2, lám. 1-3 y 1974: 7-12, 9 fig. 2). En este trabajo se hace referencia por primera vez a un

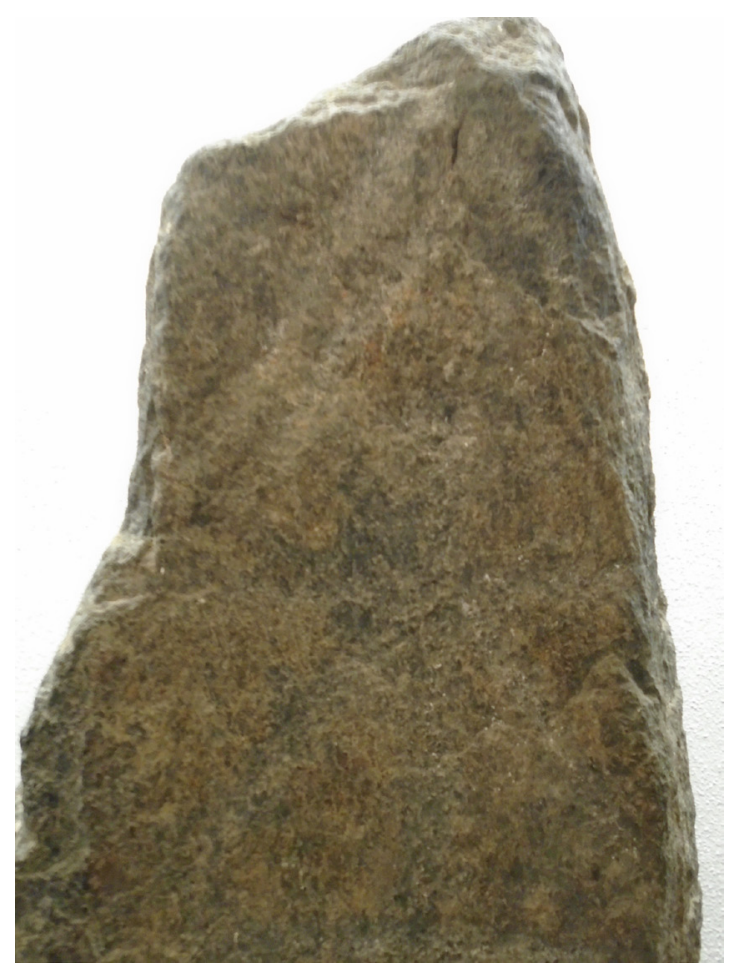

Figura 7.1b. Casco de la estela de Setefilla (Sevilla). Museo Arqueológico de Sevilla. Foto: A. Mederos.

casco con cresta o plumas, aunque indica que queda muy incierto por la erosión y no lo representó en el dibujo (Almagro Basch 1970: 322 y 1974a: 11). La presencia de servidores en el segundo sector es aceptada también por Martín Almagro Gorbea (1977: 177). Un artículo de Bendala desarrollará la hipótesis funeraria señalando que en la segunda zona el individuo tendido sería el cadáver del difunto sobre un lecho o pira, representada como un rectángulo reticulado, mientras la figura de pie con la mano en la cabeza representaría un gesto de lamentación propio de una escena de prótesis, con dos cuadrúpedos que considera cabras para ser sacrificadas en honor del muerto. En la escena inferior retoma la idea que las 7 figuras enlazadas por las manos estarían en una danza fúnebre y el auriga sería un servidor del personaje principal, aunque sugiere también que podía ser el individuo principal "en vida" sobre su carro (Bendala 1977: 193), por lo que no sería un ascenso celestial del individuo principal ya muerto. Este desarrollo ya fue claramente propuesto en trabajos posteriores, donde se menciona al carro "como vehículo 
heroizador para el viaje al mas allá" y el auriga como "el difunto mismo para emprender el viaje al más allá" (Bendala 2000: 72, 74-75 y 2013: 129-130). Como escena de prothesis es aceptada por otros autores (Gomes 1990: 80). Algunos de estos elementos han sido interpretados de forma diferente, así el rectángulo reticulado ha sido considerado una trampa de caza (Blanco, Luzón y Ruiz Mata 1969: 161), una coraza decorada retirada al difunto (Almagro Basch 1970: 321) o una alfombra (Harrison 2004: 299). Respecto a los dos cuadrúpedos han sido asociados principalmente con perros (Almagro Basch 1970: 321; Celestino 2001: 432; Harrison 2004: 299; Tejera y Fernández Rodríguez 2012: 116).

La estela volvió a ser revisada por Celestino (2001: 431-432), quien retomó la hipótesis funeraria con muerte del individuo principal en el segundo sector, acompañado de su mujer, y en la zona inferior una danza ritual de 8 individuos, uno perdido, alrededor del antropomorfo principal que montaría también el carro. En este trabajo se representa por primera vez el casco de sección triangular con dos simples trazos verticales convergentes (Celestino 2001: 431, 430 fig.), que ha sido interpretado como de tipo cónico apuntado oriental sin cresta (Gomá 2018: 68), o más correctamente, desde nuestro punto de vista, como un casco cónico apuntado con cresta cóncava triangular de tipo Bernières d'Ailly (Mödlinger 2017: 145 n. 718). El doble trazo creemos que trata de representar la cresta o cimera, en cambio Mödlinger (2017: 92) la considera una posible indicación de la protección orgánica dentro del casco. Es difícil apreciar el motivo porque hay una grapa que sujeta la pieza a la pared en el Museo Arqueológico de Córdoba y está situada justo encima del casco.

En el posterior estudio de Harrison (2004: 299-300) se indica en cambio que no aprecia ni el casco, ni un perro entre los pies del individuo principal o un anillo, elementos ya ausentes en el calco de Almagro Basch. Según su propuesta, en la segunda zona estaría una mujer velando un individuo desnudo muerto, mientras que en sector inferior el auriga iría también desnudo, y los 7 danzantes serían los hijos e hijas del difunto o bien danzarines en el funeral. Un difunto desnudo subido al carro también es visto por DíazGuardamino (2010: $\mathrm{n}^{\circ} 254$ ). Más recientemente, la figura principal ha sido considerada una "divinidad protectora", que ampara las escenas de los sectores central e inferior, considerando que el individuo muerto estaría esperando para ser incinerado junto a dos de sus perros, o bien que el cadáver estaría esperando a ser devorado por los dos perros (Tejera y Fernández Rodríguez 2012: 114, 116).

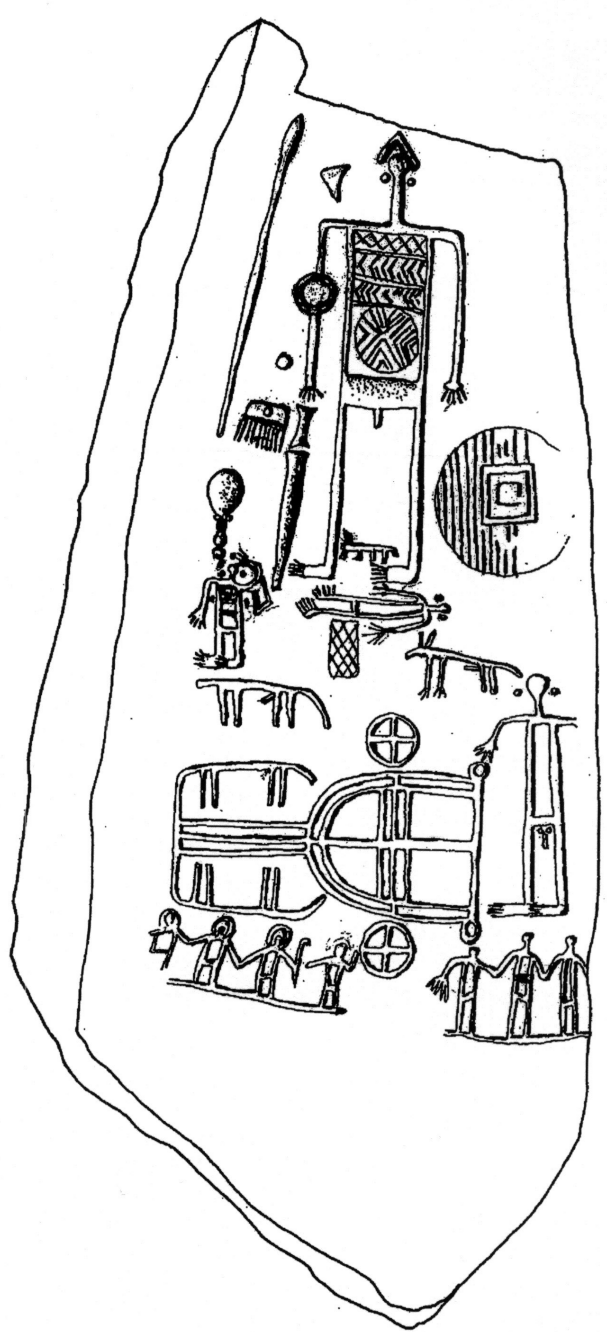

Figura 7.2a. Estela de Ategua (Córdoba) (Celestino, 2001: 430 fig.).

Por nuestra parte, ya hemos planteado que creemos que todas las figuras más pequeñas indican un grado de dependencia con el personaje principal de la estela, y dos de ellos, incluido el auriga, podrían tratarse de clientes, al igual que las 7 figuras que van cogidas de la mano, 4 mujeres y 3 hombres (Mederos y Harrison 1996: 48). En la escena central los dos cuadrúpedos serían caballos, no perros, y uno de los jinetes habría muerto, mientras el otro ha desmontado del caballo. No cabe descartar que las dos escenas cen- 
tral e inferior, sean simultáneas. La indicación del sexo en este tipo de figuras creemos que no supone que estén desnudas, sino son un formalismo gráfico para indicar el carácter masculino del individuo representado en pequeño tamaño.

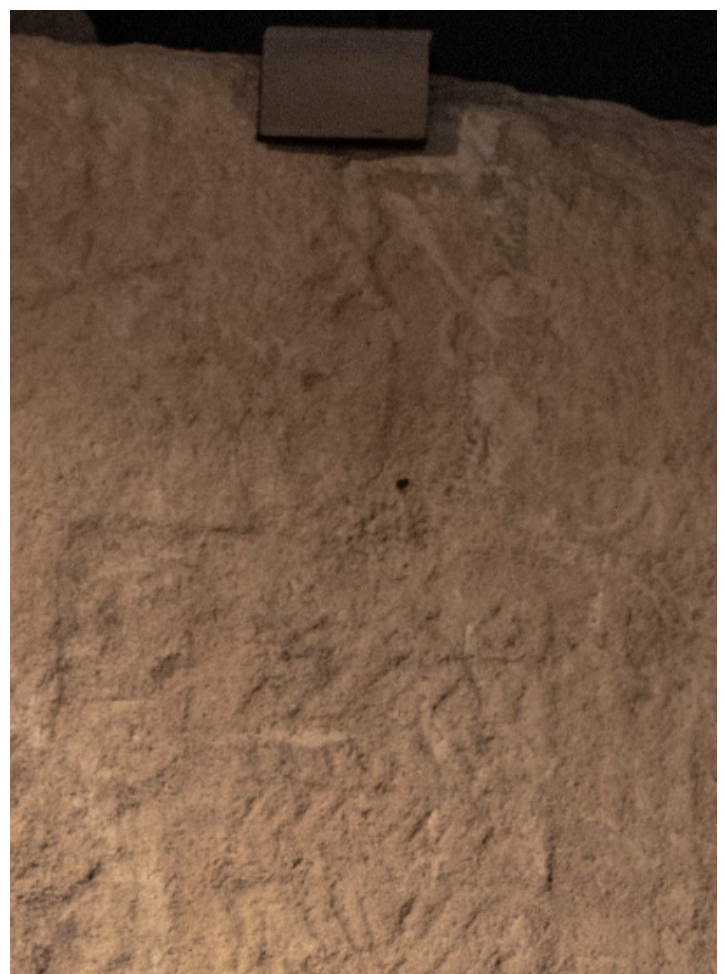

Figura 7.2b. Casco de la estela de Ategua (Córdoba). Museo Arqueológico de Córdoba.

\section{Hileras de puntos sobre la cabeza interpre- tadas como casco o tocado}

\subsection{Capilla III}

La estela de la finca de Las Yuntas, Capilla III (Badajoz) (40) (Enríquez Navascués y Celestino 1984: 238, fig. 2b, lám. 1/2; Vaquerizo 1985: 468-471, 481 fig. 2), de $1.36 \mathrm{~m}$ de altura y 0.43 $\mathrm{m}$ de ancho, es atípica porque carece de escudo y representa un arquero. A pesar de la claridad en la representación, por el tipo de soporte, aparecen elementos infrecuentes como una posible navaja con mango calado (Celestino 2001: 375; Díaz Guardamino 2010: n 269) o espejo (Harrison 2004: 246); un puñal (Celestino, 2001: 375) o cuadrúpedo (Domínguez y González Bornay 2005: 28), y un objeto rectangular que podría ser un hacha, que conocemos en la estela de Pedro Abad I, la sección de un lingote o la opinión mayoritaria como un carcaj (Celestino 2001: 375; Harrison 2004: 246; Díaz Guardamino 2010: ${ }^{\circ}$
269), pero con el problema de que no está al lado del arco y la flecha. La cabeza del antropomorfo tiene una línea de puntos rodeándola, aunque en el lado izquierdo quedan restos de un surco que quizás fuese la idea inicial que no se completó. Celestino (2001: 154, 374) cree que es un tocado, pero no descarta la idea de una diadema, e incluso considera los puntos como parte de los remaches de un casco. En cambio, Harrison (2004: 246; Díaz Guardamino 2010: $n^{\circ}$ 269) se inclina por un peinado especial o tocado. Como la estela está rota a ambos lados, tampoco cabe descartar que se hayan perdido elementos como el escudo o el carro a la izquierda de la figura antropomorfa, pues la lanza está rota y sólo se conserva la punta.

\subsection{Pedro Abad}

Un caso próximo al anterior, pero diferente, es la estela de la dehesa de Alcorrucén, Pedro Abad (Córdoba) (81), partida en su extremo inferior, con $0.87 \mathrm{~m}$ de altura y $0.52 \mathrm{~m}$ de ancho máximo conservado (Bendala, Rodríguez Temiño y Núñez 1994: 61-63, 68 fig. 1, 69 lám. 1). Presenta un antropomorfo en posición central y escudo sin escotadura en $\mathrm{V}$ en un lateral. Junto a la mano derecha figuran un espejo, una espada y un hacha, quizás de apéndices laterales, aunque Celestino (2001: 434; Harrison 2004: 301) lo considera un puñal, pero carece de punta. En la primera publicación, Bendala et alii (1994: 62) lo consideran "un machete o una daga corta". En ese trabajo no se señalaban una serie de 5 pequeñas cazoletas sobre la cabeza del antropomorfo, que sí figuran en el calco de Celestino (2001: 433-434 fig.). Estos puntos son dudosos porque hay otras pequeñas cazoletas en la superficie de la estela, dos sobre el mango de la espada o seis sobre un segundo antropomorfo, los cuales suelen interpretarse como pesos, aunque podrían ser elementos astrales. Por otra parte, Harrison (2004: 301) no ve en la fotografía los 5 puntos sobre la cabeza y las 2 pequeñas cazoletas sobre el mango de la espada, los cuales considera un primer intento de grabar la espada. Estos puntos que rodean la cabeza están más distanciados de ella y separados entre sí, lo que hace discutible que pudiesen asignarse a un casco o un tocado.

\section{Representaciones dudosas de cascos}

\subsection{Solana de Cabañas}


Existe una serie de motivos que a veces se han asociado con un casco pero cuya atribución creemos que no es correcta o resulta muy difícil de valorar. Es el caso de la estela de Solana de Cabañas (Cabañas del Castillo, Cáceres) (22), de $1.29 \mathrm{~m}$ de altura y $0.67 \mathrm{~m}$ de ancho (Rosso 1898: 179-182; Almagro Basch 1966: 27-29, fig. 2, lám. 1). El primer investigador en considerar la presencia de un casco sobre el hombro derecho fue Almagro Basch (1966: 29), interpretado como de tipo apuntado oriental sin cresta por Almagro Gorbea (1989: 281), o bien cónico con cresta de tipo Biebesheim (Mödlinger 2017: 145 n. 716). Tiene algunas dudas Celestino (2001: 152, 349), pero cree que no se trata de una fíbula al faltar el resorte y la aguja, por lo que se inclina por un casco cónico. En cambio, la fíbula es la opción defendida por Díaz-Guardamino (2010: $\left.\mathrm{n}^{\circ} 341\right)$. No se pronuncia Harrison (2004: 219) sobre el objeto, aunque no descarta ni el casco, ni la fíbula, e incluso sugiere una alternativa, una copa de beber, que en este caso quedaría inclinada. Debe tenerse en cuenta que muchas veces las fíbulas son representadas de manera muy sencilla, no se indica el resorte y a veces al tratarse de un trazo continuo tampoco se precisa la punta de la aguja. Nosotros creemos que se trata de una fíbula, pues siempre se sitúa encima del hombro del antropomorfo, normalmente el derecho, aunque hay excepciones en el izquierdo por problemas de espacio en la composición, y como ya hemos planteado podría ser una fíbula de codo asimétrico descentrado, representada invertida con el codo hacia abajo (Mederos y Jiménez Ávila 2016: 125).

\subsection{Cabeza de Buey III}

Un caso parecido a Solana de Cabañas es la representación en la estela de la finca El Corchito, Cabeza de Buey III (Badajoz) (34) (Almagro Gorbea 1977: 172 fig. 69.6), con escudo y por debajo un antropomorfo con espada en el cinto, de $0.99 \mathrm{~m}$ de altura y 0.52 $\mathrm{m}$ de ancho. Entre los motivos representados, Celestino (2001: 193 367) identifica un casco, aparentemente cónico con cresta de tipo Biebesheim (Mödlinger 2017: 91 fig. 2.16/5, 145 n. 716). En cambio, Almagro Gorbea (1977: 171) y Díaz Guardamino (2010: $\mathrm{n}^{\circ}$ 264) lo asocian con una fíbula, al igual que hemos planteado nosotros, pues se encuentra en posición sobre el hombro derecho del antropomorfo. Concretamente se trataría de una fíbula de codo asimétrico descentrado, sin indicación de resorte o aguja (Mederos y Jiménez Ávila 2016: 125).

\subsection{El Viso II}

La estela de la finca de Las Mangadas, El Viso II (Córdoba) (55) tiene $0.76 \mathrm{~m}$ de altura y $0.68 \mathrm{~m}$ de ancho (Bendala, Hurtado y Amores 1979-80: 383, 385, 386 fig. 2, lám. 11). Presenta escudo con escotadura en V externa y al lado un antropomorfo con espada al cinto con un tamaño similar. Se ha interpretado por Celestino (2001: 153-154, 397) como un casco cuyo trazo no sólo cubre la cabeza sino también el hombro derecho y el arranque del brazo. En cambio otros autores no interpretan este motivo (Bendala et alii 1979-80: 386 fig. 2; Galán 1993: 106 nº 59; Díaz-Guardamino 2010: $n^{0}$ 294), a veces justificándolo por no haber podido ver la estela directamente (Harrison 2004: 265). Creemos que es la interpretación como casco es muy dudosa, porque como la propia descripción muestra, pudiera tratarse de un intento previo de grabar el antropomorfo, lo que explicaría que el trazo se extienda al hombro y arranque del brazo derecho.

\section{Discusión}

La presencia de los primeros cascos la encontramos en una serie de estelas que han sido publicadas mayoritariamente en los últimos años, Aldeia Velha (Sabugal, Beira Alta) (2011), Baracal (Sabugal, Beira Alta) (2011), Zebros (Zebreira, Beira Baixa) (2012) y Fundão (Beira Baixa) (2015), que se han sumado a la más conocida de Santa Ana de Trujillo (Cáceres) (1942). Aunque sólo dos de ellas presentan el casco cónico apuntado con cresta bien conservado, Fundão y Santa Ana de Trujillo, en Baracal II y Zebros se conserva parcialmente la parte inferior del casco, mientras en Aldeia Velha el casco está casi completo pero ha sido modificado posteriormente con la adición de otros motivos. La coherencia interna de este grupo de estelas ha pasado desapercibida y recientemente de todas estas estelas sólo se consideraba por Gomá (2018: 76) que presentaban cascos la estela de Santa Ana y era dudoso en el caso de Aldeia Velha. 


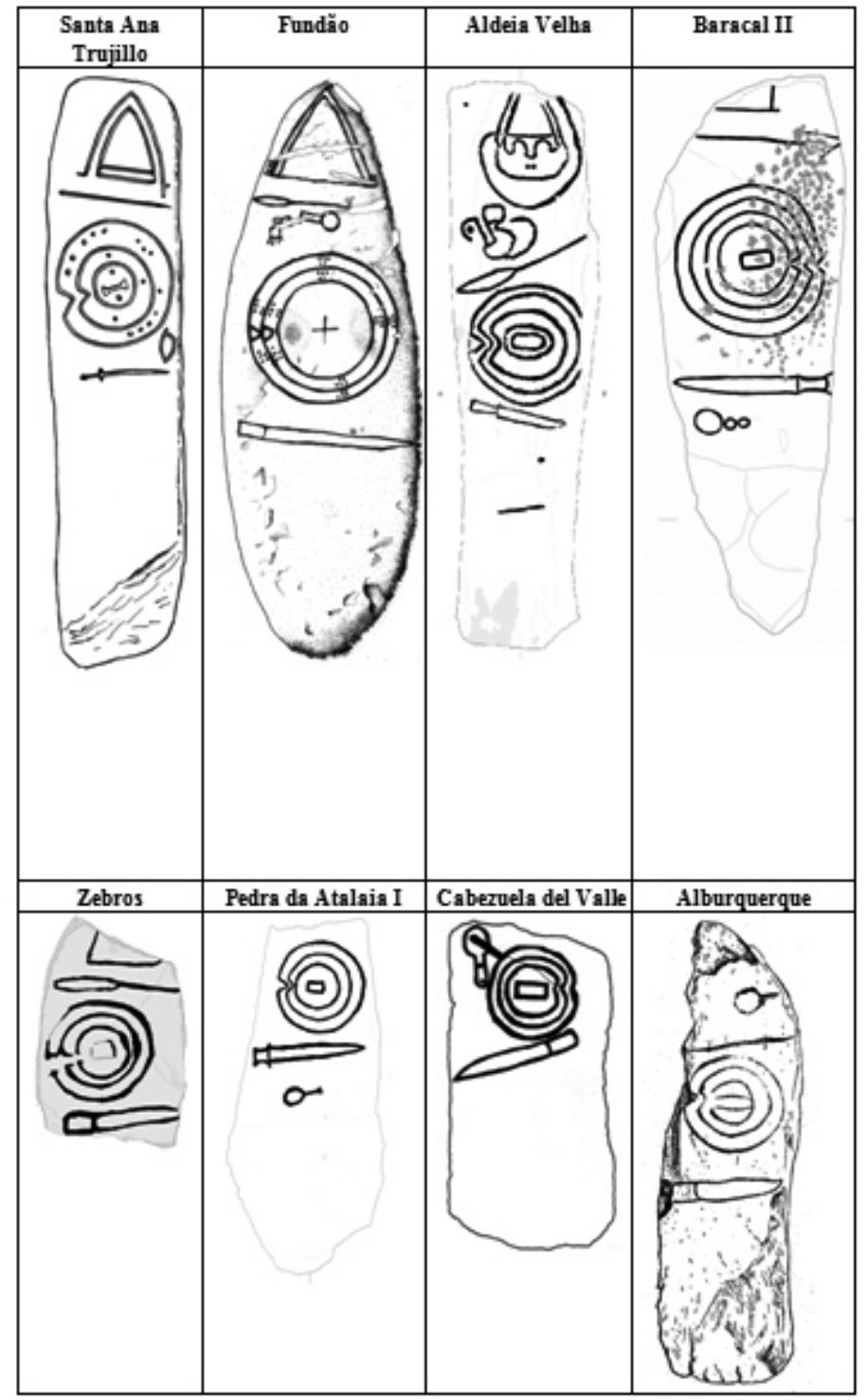

Fig. 8. Fase II de las estelas del Suroeste incorporando casco de cresta y espejo a las estelas tripartitas con lanza, escudo y espada.

Por otra parte, el casco está también acompañado por el espejo en Fundão, Santa Ana de Trujillo y Baracal II, en Aldeia Velha pensamos que esta parcialmente oculto por la adición de otro motivo superpuesto, mientras en Zebros la fractura inferior de la estela impide saber si el motivo del espejo existió, que no cabe descartar. De ellos es especialmente interesante el espejo de Baracal II porque presenta dos engrosamientos circulares en el mango que sugieren un espejo importado.

A este grupo cabe añadir otras tres estelas que están rotas en la parte superior pero que tienen una iconografía similar y pudieron tener también un casco cónico apuntado con cresta, caso de Pedra da Atalaia I (Beira Alta) (2011), Cabezuela del Valle (Cáceres) (2011) y Alburquerque (Badajoz) (1923), que también presentan espejo.

En ocasiones, los espejos tienen el mango calado como en Cabezuela del Valle, típico en los espejos sardos de bronce, el mejor conservado de San Pietro (Torpè), pero con el mango completo de Abini (Teti), Santa Vittoria (Serri), Costa Nighedda (Oliena) y S'Iscolca (Ozieri) (Lo Schiavo 1989: 125 fig. 10/1-4, 8-9, 11, 1991: 217 fig. 2/1-4, 8-9, 11 y 2014: 147 fig. 6). 


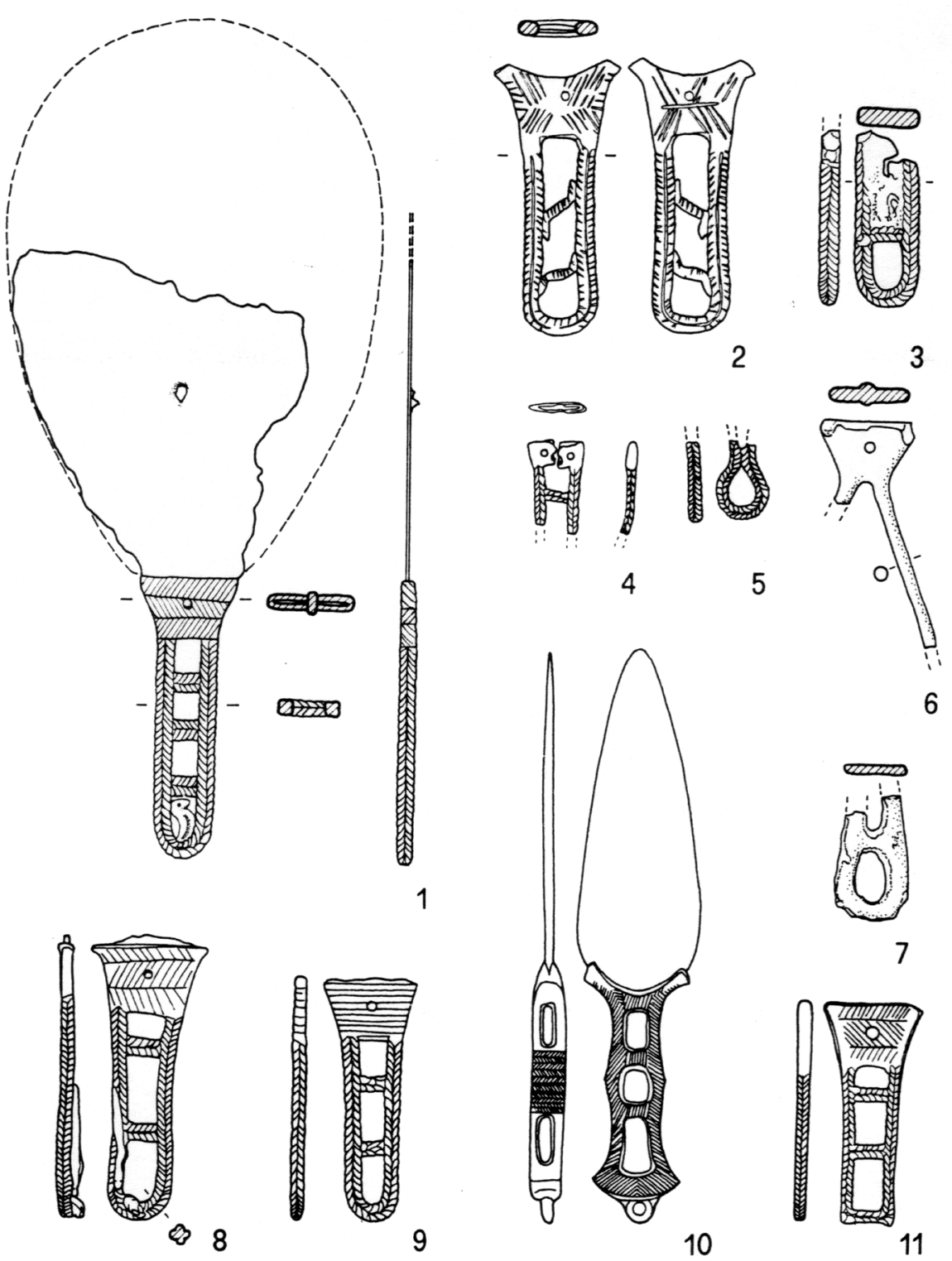

Figura 9. Mangos calados de espejos en Cerdeña: 1) Nuraghe S. Pietro, Torpè. 2) Costa Nighedda, Oliena. 3) Colección Cara. 4) Sa Sedda 'e Sos Carros, Oliena. 5, 8 y 10) Albini, Teti. 6 y 11) Santa Vittoria, Serri. 7) Monte Sa Idda, Decimoputzu. 9) Colección Spano (Lo Schiavo 1989: 125 fig. 10/1-11).

En general, este importante conjunto de estelas que se extiende desde Sabugal (Beira Alta), casi en la frontera hispano-lusa con Salamanca, hasta Badajoz, presenta como elementos comunes la presencia de casco cónico apuntado con cresta, lanza, escudo con escotadura en $\mathrm{V}$ externa sin remaches en el interior, espejo y espada. Esta última es especialmente significativa porque normalmente presenta un enmangue rectangular en Zebros, Fundão, Cabezuela del Valle o Alburquerque, y aunque no tienen los remaches, sugiere una posible es- pada Rosnöen con cronologías del 1325-1150 AC. Hay dos ejemplares algo más recientes, Fundão y Santa Ana de Trujillo, porque presentan remaches en el escudo con escotadura en $\mathrm{V}$ exterior. Esto no implica que en el futuro pueda aparecer algún tipo de casco más antiguo en una estela de iconografía similar, por ejemplo un casco cónico con cresta incipiente o incluso un casco metálico redondeado hemiesférico sin cresta, que podría ser el caso de Zebros donde no hay doble trazo para indicar una cimera. 
Este es un panorama muy diferente al que se sugería hace casi dos décadas (Celestino 2001: 152), cuando se planteaba que en la denominada Zona I, que llegaría hasta el valle del Tajo y la Sierra de Montánchez (Cáceres), la única estela con una importación foránea, por la presencia de un espejo, era la de San Martín de Trevejo (Cáceres).

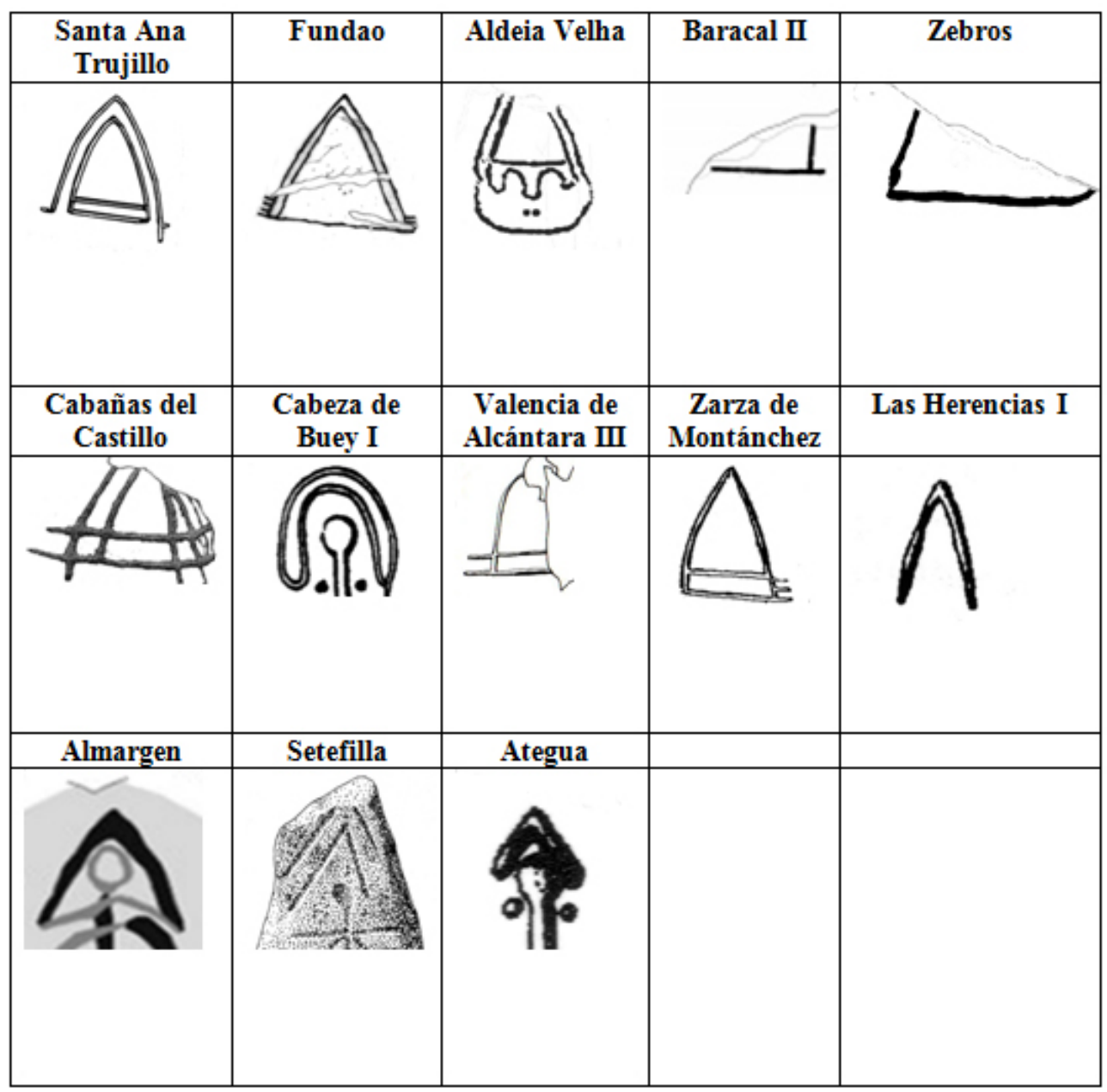

Fig. 10. Cascos cónicos apuntados con cresta representados en las estelas del Suroeste de la Península Ibérica.

La fase siguiente corresponde a estelas con escudo central que tienen escotadura en $\mathrm{V}$ externa y remaches en su interior, lanza por encima y antropomorfo por debajo acompañado por una espada pistiliforme cerca de la mano, que siguen utilizando cascos apuntados cónicos con cresta y persiste el espejo. Las estelas que disponemos son Cabañas del Castillo (Cáceres), Cabeza de Buey I (Badajoz) y quizás Valencia de Alcántara III (Cáceres), si se acepta que es un casco y no una fíbula o un carro, tercera opción que es la que preferimos.

Estas estelas presentan nuevos elementos iconográficos como el carro con dos ruedas en Cabeza de Buey I y quizás en Valencia de
Alcántara III (Mederos 2008), aunque algunos investigadores creen que no comienzan hasta el inicio del Bronce Final IIIA, desde el 1050 AC (Torres 2012: 461), o la presencia de fíbulas de codo asimétrico descentrado en Cabañas del Castillo y Cabeza de Buey I (Mederos y Jiménez Ávila 2016: 124-125, 132).

En la siguiente etapa en estelas, donde el escudo y el antropomorfo tienen similar importancia, quizás ya hacen su aparición los cascos cónicos apuntados con cresta cóncava triangular, pero sin datos de detalle porque aparecen figurados como dos trazos convergentes formando un triángulo muy esquemático sobre la cabeza. El más preciso es el de Zar- 
za de Montánchez, pero no se indica la cresta que lo sugiere su forma apuntada, aunque sí se indican en uno de los lados 2 o 3 remaches decorativos. Los escudos presentan la escotadura en $\mathrm{V}$ al interior y no se marcan remaches en su interior. La espada es uno de los indicadores cronológicos más importantes pues tanto en Zarza de Montánchez, como la posible espada, transformada en antropomorfo en Las Herencias I, apuntan a una espada pistiliforme, aunque con tendencia a lados paralelos, espada que parece que está ausente en la estela de Almargen.

La fase final de las estelas con cascos de cresta corresponde a estelas donde el antropomorfo tiene un papel preeminente, siendo el ejemplo más evidente la estela de Ategua con un escudo ya sin escotaduras a un lado, junto a la mano izquierda, o la estela de Setefilla donde el escudo esta a sus pies. La espada ya se sitúa en el cinto en Setefilla, pero es muy esquemática, o cerca de la mano derecha del guerrero en el caso de Ategua y su forma parece remitir a las espadas de tipo Huelva. El casco de Setefilla es particularmente interesante porque, a pesar de su esquematismo, los dos trazos paralelos indican la presencia de un casco cónico apuntado con cresta cóncava triangular.

\section{Conclusiones}

El casco era un elemento fundamental de la panoplia del guerrero y una posesión muy precia$\mathrm{da}$, que pasaba de un guerrero a otro con una biografía propia, que era siempre recordada y transmitida oralmente. "Meríones dio a Ulises (...) un morrión fabricado de bovina piel. En su interior, múltiples correas lo tensaban (...) y el fondo estaba forrado de fieltro. De Eleón se lo había llevado en cierta ocasión Autólico, que lo robó horadando la espesa casa de Amíntor Orménida. Lo llevó a Escandea y se lo dio a Anfidamante de Citera. Anfidamante se lo dio a Molo como presente de hospitalidad. Éste se lo había dado a su hijo Meríones para que lo llevara. Y en ese momento (...) tocaba la cabeza de Ulises" (Hom., Il., X, 260-271).

Su importancia se refleja también en el uso de cascos que son mencionados en 87 ocasiones en la Iliada. En 41 casos asociados a guerreros aqueos y en 38 casos a guerreros tro- yanos, además de 3 imprecisos y 5 ejemplos donde el casco es utilizado por una divinidad, 3 veces por Ares y en 2 ocasiones por Atenea, quien porta un casco de oro. El más citado es el casco del troyano Hector en 12 ocasiones, que supera claramente a los de Aquiles con 8 menciones, Agamenon con 4, Patroclo con $3 \mathrm{u}$ Odiseo con 3 y en todos ellos se trata de cascos con cresta. El asedio de Troya duró unos 10 años, entre $c a$. 1196-1186 AC (Mederos 2007: 95-98 tabla 1).

La revisión de las estelas con casco de cresta de la fachada atlántica de la Península Ibérica muestra que hay muchos más ejemplos y más antiguos de los que habitualmente se suponen y compensan la escasez de hallazgos de piezas metálicas en comparación con los depósitos franceses o las tumbas italianas (Egg y Tomedi 2002: 555 fig. 12; Brandherm 2011: 41 fig. 1; Mödlinger 2017: 21 fig. 2.1).

No es fácil valorar como se ha producido la llegada de los primeros prototipos de cascos cónicos apuntados de cresta a la Península Ibérica que parecen ser similares a los del Bronce Final I francés. Una ruta terrestre y posible origen en el norte de Italia fue defendida por Almagro Basch (1966: 68), relacionándolos con los cascos itálicos de Veii o Tarquinia de época vilanoviana, que habrían llegado a la Península Ibérica con las invasiones de los Campos de Urnas de Hallstatt B, no anteriores al 800 a.C. Un origen en los Alpes es sugerido por Gomá (2018: 68) sin mucho detalle, pero debe apoyarse en las cronologías sugeridas para los cascos de cresta de tipo Lueg de los Alpes austriacos que se atribuyen a partir del Bronce C (Egg y Tomedi 2002: 556-557; Brandherm 2011: 43, 42 fig. 2 y 2013: 137). Con un origen centroeuropeo se ha defendido una ruta terrestre por Dirk Brandherm (2016: 187, 188 fig. 6.7/6) por influencias de los Campos de Urnas occidentales, que sería sugerida por la presencia de cremaciones asociadas con las estelas del Suroeste en Solana de Cabañas (Cáceres) y a restos muy descompuestos en Granja de Céspedes (Badajoz), la presencia de una espada importada de tipo Rixheim en la ría de Huelva, de hachas de alerones de tipo Grigny en Arroyomolinos (Jaén), una navaja de tipo Proto-Vilanoviano de Beja o por la decoración de algunas urnas cerámicas. 


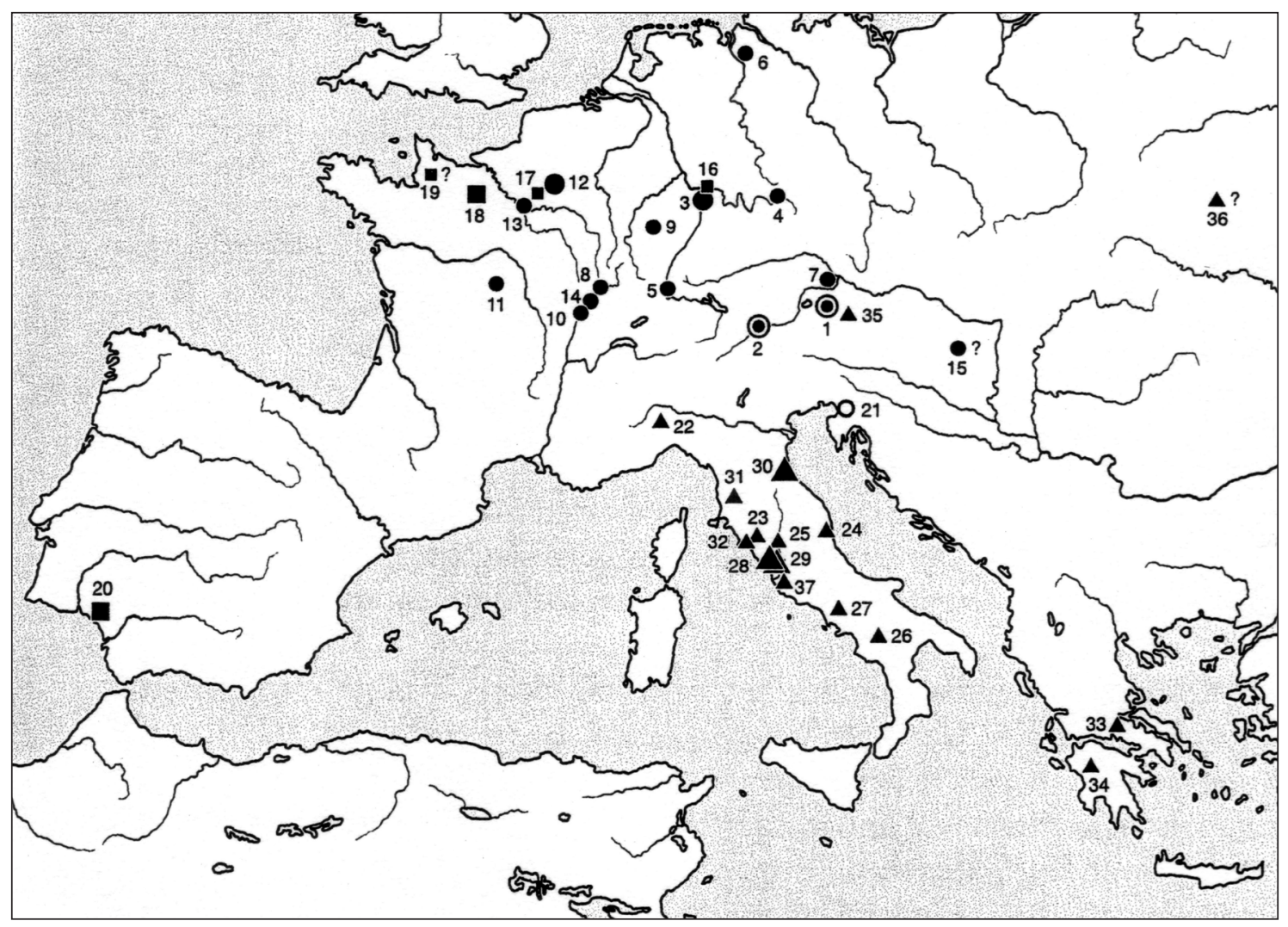

Figura 11. Distribución de los cascos del Bronce Final en Europa, ejemplares italianos con un triángulo. 1) Pass Lueg. 2) Piller. 3) Biebesheim. 4) Ebing. 5) Kleinhüningen. 6) Lesum. 7) Pockinger Heide. 8) Auxonne. 9) Blainville. 10) Chalon-sur-Saône. 11) Le Theil. 12) Montmacq. 13) Seine, Paris. 14) Seurre. 15) Angeblich, Hungría. 16) Mainz-Kostheim. 17) Armancourt. 18) Bernières d’Ailly. 19) Angeblich, Normandía. 20) Ría de Huelva. 21) Skocjan. 22) Asti. 23) Bisenzio. 24) Fermo. 25) Narce. 26) Sala Consilina. 27) Santa Maria di Capua Vetere. 28) Tarquinia. 29) Veii. 30) Verucchio. 31) Volterra. 32) Vulci. 33) Delfos. 34) Olimpia. 35) Hallstatt. 36) Zavadintsy. 37) Osteria dell'Osa (Egg y Tomedi 2002: 555 fig. 12).

A estas conexiones centroeuropeas podría incluso añadirse la presencia de una estela con escudo de escotadura en $\mathrm{V}$ interior y una lira en Luna (Zaragoza) (Fatás 1975: 165-169, lám. 1-3) y en particular la aparición de la cremación en la Península Ibérica asociada a estelas no decoradas en la fase I de Herrería (Guadalajara) hacia el 1350 AC (Cerdeño y Sagardoy 2016: 210, tabla 12). Sin embargo, tampoco podemos descartar una ruta marítima atlántica que debía ser transitada regularmente por embarcaciones y que también sugiere la proximidad a la costa de los hallazgos de la ría de Huelva y Vila Cova de Perrinho (Beira Litoral).

Desde fechas entre 1275-1225 AC, ya iniciado el Bronce Final IIA (Mederos 1997: 77 tabla 2), o Bronce Final I, fase isla de Cheta o Rosnöen (Brandherm y Mederos 2014: 84 fig. 5), 12601200 AC (Brandherm 2007: 12; Harrison 2004:
14) o 1250/1200-1100 AC (Ruiz-Gálvez 1998: 208), debió surgir la segunda fase de las estelas atlánticas con la incorporación de dos nuevos elementos gráficos, los cascos metálicos con cresta y los espejos de bronce, que coexistirán con las estelas de iconografía tripartita con escudo, lanza y espada las cuales debieron comenzar hacia el 1325-1300 AC según los modelos de espada (Mederos 2012: 424-430). Otros investigadores consideran que los espejos quizás se remonten hasta 1350 , perviviendo hasta el $850 \mathrm{AC}$, mientras los cascos cónicos de cresta aparecerían después, entre el 1175-1150 AC continuando hasta el 825 AC (Brandherm 2013: lám. 11). Fechas más recientes para la aparición de los cascos son propuestas entre el 1100-900 AC (Vilaça, Osorio y Santos 2011: 352) -pero cuando figuran los espejos serían a partir del 1000 AC (Santos, Vilaça y Marques 2011: 329)-, 1000 AC (Almagro Gorbea 1998: 283), 1000-900 AC (Almagro 
Gorbea 1998: 94; Ruiz-Gálvez y Galán 2017: 58), 1000-800 AC (Harrison 2004: 139), desde el 950 AC (Celestino 2001: 156; Rodríguez y González Bornay 2018: 1466), 900-800 AC (Almagro Gorbea 1973: 359) o 710-650 AC (Chapa y Pereira 2016: 365).

Si los primeros cascos cónicos apuntados con cresta deben relacionarse con la existencia de redes comerciales atlánticas, la simultánea aparición de los espejos, de tradición micénica, que pudieron llegar también con intermediación chipriota o sarda (Lo Schiavo, MacNamara y Vagnetti 1985; Mederos 2002), implica que ambas redes comerciales confluían en la fachada atlántica de la Península Ibérica.

Estas influencias mediterráneas son contemporáneas al Heládico Final IIIB, quizás una vez producida la caída de algunos sistemas palaciales en el Egeo, pues hay varios niveles de destrucción durante el Heládico Final IIIB1 (French 1967), y la llegada de espejos debió ser principalmente en la fase 1285/1270-1225/1220 AC (Mederos 1999: 237-238), antes de comenzar una fase de mayor inestabilidad en el Mediterráneo Oriental entre 1225-1175 AC (Dothan y Dothan 1992; Vagnetti 2000; Mederos 2007). La presencia de cerámica del Heládico Final IIIB1 en Nuraghe Antigori (Ferrarese Ceruti et alii 1987) sugiere que también productos sardos pudieron llegar en barcos chipriotas o micénicos hasta el Atlántico.

Para la aparición de los cascos de cresta en Europa hay dos propuestas evolutivas. Por una parte está la propuesta de una evolución a partir de los cascos de cresta incipiente de tipo Mantes (Seine-et-Oise, Francia) (Mödlinger 2017: 99, 107), en el río Sena, localizado en 1860. También se incluyen uno de Mainz (Hessen, Alemania), en el estuario de los ríos Main y Rin, descubierto en 1917; otro de Weil am Rhein (Baden-Württemberg, Alemania), en el río Rin -también denominado Kleinhüningen (Basilea, Suiza)-, hallado en 1910 y un cuarto de Oggione-Ello (Lombardía, Italia), descubierto en una cantera antes de 1929, que presenta materiales probablemente asociados del Bronce $\mathrm{D}$, proponiéndose una fecha de finales del Bronce $\mathrm{C} y$ transición al Bronce D (Mödlinger 2017: 102$103 \mathrm{n}^{\mathrm{o}} 79-82$ ).

La segunda hipótesis es a partir de los cascos de cresta con tres puntas de tipo Lueg, descu- bierto en 1838 el primer ejemplar en Pass Lueg (Salzburgo, Austria), al que recientemente se han incorporado dos nuevos ejemplares, uno en 2001 en Piller Statel (Tirol, Austria) (Egg y Tomedi 2002) y otro procedente de Anlauftal (Salzburgo, Austria), descubierto en 2006 (Lippert y Mehofer 2010: 51 fig. 2/1; Lippert 2011; Mödlinger 2017: 107-109 $\mathrm{n}^{\mathrm{o}}$ 83-85). Estos cascos han sido datados en el Bronce C por Egg y Tomedi (2002: 556), mientras Brandherm (2011: 42 fig. 2) lo considera el modelo continental más antiguo, que surgiría hacia 1375 AC. Otros autores prefieren optar por un Bronce $\mathrm{C} / \mathrm{D}$ y preferiblemente Bronce D2 o Hallstatt A1 (Mödlinger 2017: 106-107), Bronce D (Schauer 1979-80) e incluso un Hallstatt B1, después 1030 AC (Lippert 2011: fig. 24), criticado por Tomedi y Egg (2014: 49, 51).

Los cascos redondos con cresta de tipo Mantes evolucionarían hacia los cascos cónicos apuntados con cresta, que con su mayor altura separan más la cabeza de la parte superior del casco que puede recibir el impacto de una espada. Son denominados de tipo Biebesheim (Hessen, Alemania) por Schauer (1979-80: 533), Lippert (2011: 40-45) y Mödlinger (2017: 109 tabla 2.12), dos cascos hallados en el antiguo cauce del río Rin en 1963. No obstante, hay otros ejemplos bien conocidos como el casco de Le Theil en Billy (Allier, Loir-et-Cher, Francia), localizado en 1875, pero que había perdido su parte superior (von Merhart 1940: 16, 17 fig. 3/1), los dos de Montmacq (Oise, Francia), localizados en 1921 en el dragado del río Oise, Auxonne (Côte d'Or, Francia) (von Merhart 1940: 16, 17 fig. 3/6; Blanchet 1984: 262 fig. 143, 263 fig. 144), uno en el río Sena (París, Francia) anterior a 1911 (von Merhart 1940: 16, 17 fig. 3/7), el de Blainville-sur-l'Eau (Meurthe-et-Moselle, Francia), el más grande conocido con $32.5 \mathrm{~cm}$ de altura (Coutil 1927: 363 fig.; von Merhart 1940: 16, 17 fig. 3/4), otro de Pockinger Heide (Griesbach, Baviera) localizado antes de 1851 (von Merhart 1940: 16, 17 fig. 3/3) o en el río Lesum en Kreis BremenBlumenthal (Bremen, Alemania) en 1938 (von Merhart 1940: 16, 17 fig. 3/2) entre otros, pero en ningún caso se extienden al Sur de Francia o a la fachada atlántica (Mödlinger 2017: 112 fig.2.23, 114-116 $\mathrm{n}^{\circ} 86-100$ ). 

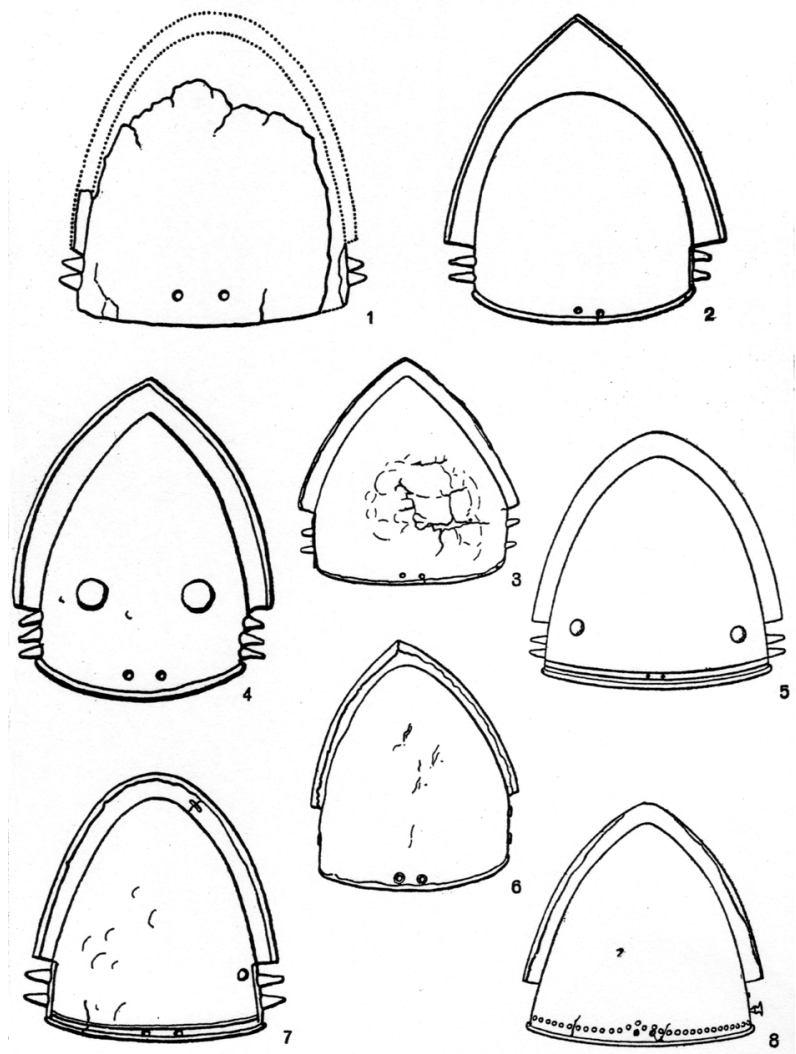

Figura 12a. Cascos cónicos apuntados con cresta convexa: 1) Le Theil. 2) Lesum. 3) Pockinger Heide. 4) Blainville. 5) Montmacq. 6) Auxonne. 7) Seine, Paris. 8) Montmacq (von Merhart 1940: 17 fig. 3/1-8).

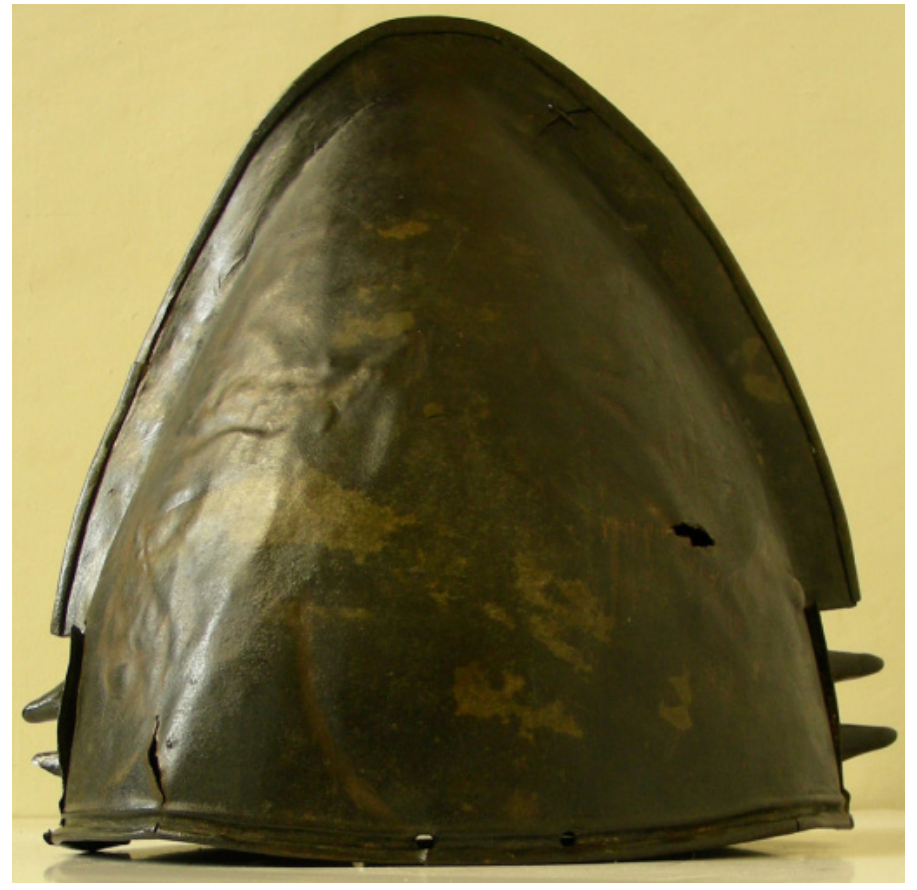

Figura 12b. Casco cónico apuntado con cresta convexa del río Sena (París, Francia), inv. $n^{\circ}$ 358. Museo de Arqueología Nacional, Saint-Germain-en-Laye. 
La cronología de estos cascos viene definida sobre todo por el depósito de Le Theil con objetos asociados, en particular un hacha de alerones medianos, que se sitúa en el Bronce Final I francés (Blanchet 1984: 261) o finales del Bronce Final I e inicios del Bronce Final II, coetáneo con Ha A1 (Coffyn 1985: 171), pues las hachas de alerones medianos suelen aparecer asociadas en depósitos de fase Rosnoën del Bronce D2 y Hallstatt A1 (Mödlinger 2017: 113), que lo haría para esta autora contemporáneo de los cascos de tipo Lueg. Sin embargo, otros investigadores proponen fechas algo más elevadas de Hallstatt A (von Merhart 1940: 24, 38; Brandherm 2011: 43) o incluso Hallstatt B1 (Schauer 1979-80: 533). No obstante, se propone una cierta evolución cronológica y así el casco del río Sena se asigna al $1225 \mathrm{AC}$ y el de Le Theil se sitúa en torno al 1150 AC (Brandherm 2011: 42 fig. 2).

La fase siguiente de las estelas del Suroeste corresponde a estelas con escudo central con escotadura en $\mathrm{V}$ externa y remaches en su interior, lanza, antropomorfo por debajo con espada pistiliforme cerca de la mano y espejo, durante la cual se siguen utilizando cascos apuntados cónicos con cresta de de tipo Biebesheim, siendo la estela más representativa la de Cabañas del Castillo que presenta indicada tanto la cresta como dos remaches decorativos a ambos lados.

Esta fase corresponde al Bronce Final IIB, 1225-1150 AC (Mederos 1997: 77 tabla 2), o Bronce Final IIA, fase de Huerta de Arriba con espadas tipo Vilar Maior y el Bronce Final IIB con espadas tipo Catoira (Brandherm y Mederos 2014: 84 fig. 5), 1200-1130 AC (Brandherm 2007: 12; Harrison 2004: 14), 1100-940 AC (Ruiz-Gálvez 1998: 208) o incluso un 900800 AC para la estela de Cabañas del Castillo (Rodríguez y González Bornay 2018: 1466).

Una nueva etapa comienza con las estelas donde el escudo y el antropomorfo tienen similar importancia, durante la cual hacen acto de presencia quizás los primeros cascos cónicos apuntados con cresta cóncava triangular. Estas estelas las situamos en el Bronce Final IIC, 1150-1050 AC (Mederos 1997: 77 tabla 2), o Bronce Final IIC, fase Hío con espadas pistiliformes (Brandherm y Mederos 2014: 84 fig. 5), 1130-1050 AC (Brandherm 2007: 12; Harrison 2004: 14). Esto sugiere que los cascos con cresta podrían comenzar a aparecer antes de lo que habitualmente se supone, pues habían sido situados hacia el 1025-850
AC para las estelas del Suroeste (Brandherm 2013: lám. 13).

Los cascos de tipo Bernières d'Ailly prolongan la cresta a casi la totalidad del casco dándole mayor estabilidad conformando un perfil de forma triangular y su altura oscila entre 22 y 29 cm (Milcent 2012: 131; Mödlinger 2017: 117 tabla 2.13). El nombre deriva del principal hallazgo, el depósito de Bernières d'Ailly (Calvados, Francia) con 9 cascos localizados en 1832 en tres agrupaciones de 3 cascos, del que se perdió el resto del material asociado como dos puntas de lanza y un hacha con alerones (von Merhart 1940: 16, 18 fig. 4/3-8; Hencken 1971: 66-72 fig. 40-45). Otros autores prefieren denominarlos de tipo Mainz-Kostheim (Hessen, Alemania) (Lippert 2011: 32, fig. 22) por el casco hallado en el río Rin junto a Mainz antes de 1940 (Merhart 1940: 16, 16, 18 fig. 4/1; Hencken 1971: 72, 73 fig. 47), o de tipo Armancourt (Oise, Francia) (Sperber 2011: 37 fig. 12/2), localizado dragando el río Oise en 1913-14 (Merhart 1940: 16, 16, 18 fig. 4/2; Hencken 1971: 66, 67 fig. 39; Blanchet 1984: 316, 317 fig. 176).

Otros ejemplares se hallaron en Nemours (Seine-et-Marne, Francia), sin contexto conocido (Mödlinger 2017: 122 n $^{\circ}$ 113) o el más reciente en Roxheim, Ludwigshafen (Rheinland-Pfalz, Alemania) junto al río Rin (Sperber 2006: fig. 7.14). A ellos cabe unir un remache en el depósito de Larnaud (Jura, Francia) (Hencken 1971: 75 fig. 49a), o los fragmentos ya mencionados de la Península Ibérica procedentes del pecio o depósito de Huelva, que aporta el mejor conjunto de material asociado (Hencken 1955-56: 228, 225 fig. 1, 227 lám. 1/2) y de Vila Cova de Perrinho (Brandão 1963: 118, lám. 1/9-11).

Aunque tradicionalmente se le daba a estos cascos cronologías bastante recientes, entre el 800-700 a.C. (Hencken 1971: 74; Blanchet 1984: 316), actualmente se sitúa entre el Bronce Final II reciente o el Bronce Final III antiguo (Milcent 2012: 131, 213). Las cronologías más antiguas las propone Lippert (2011: 32 fig. 22), 1300-1200 AC, mientras por un 1200-1100 AC se inclina Mödlinger (2017: 121) quien defiende que aparecerían durante Hallstatt A1 y desaparecerían a finales de Hallstatt B1. En cambio, Dirk Brandherm (2011: 42 fig. 2 y 2013: lám. 11) propone un desarrollo escalonado desde el 1025/1000 $\mathrm{AC}$ con los cascos del depósito de Bernières d'Ailly con perfil de forma triangular, que ha- 
rían su aparición en la Península Ibérica simultáneamente, hasta ejemplares más tardíos como el de Armancourt, con un perfil trian- gular más anguloso hacia el $875 \mathrm{AC}$, que se aproxima más a los cascos italianos y podrían pervivir hasta un $825 \mathrm{AC}$.
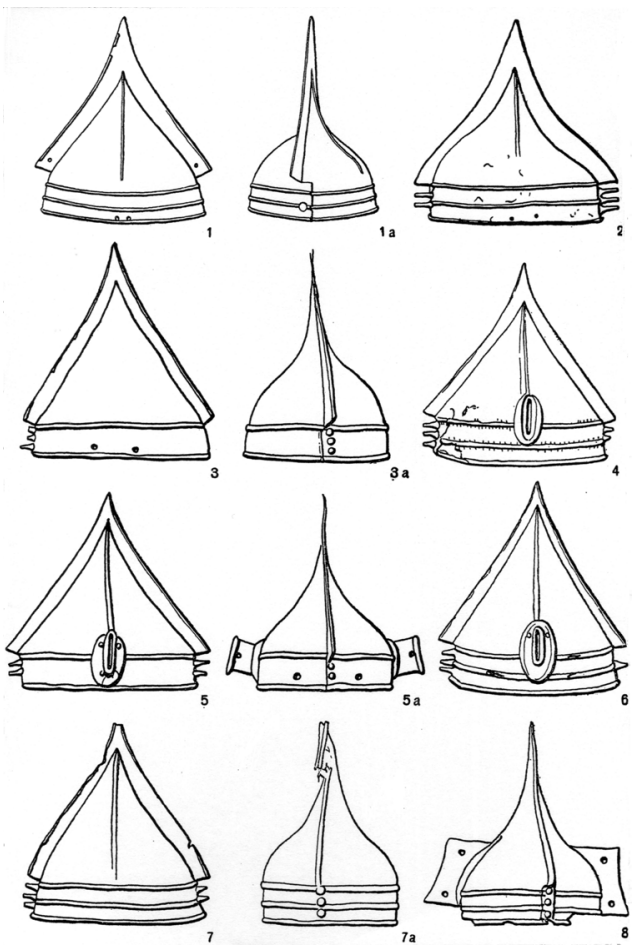

Figura 13a. Cascos cónicos apuntados con cresta cóncava: 1) Mainz-Kostheim. 2) Armancourt. 3-8) Bernières d'Ailly (von Merhart 1940: 18 fig. 4/1-8).
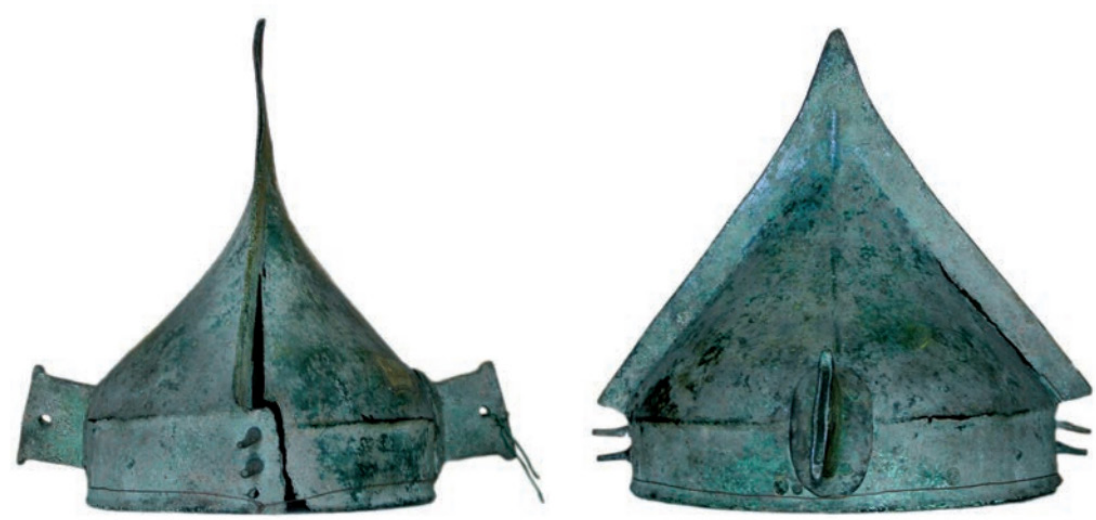

Figura 13b. Casco cónico apuntado con cresta cóncava de Bernières d’Ailly (Calvados, Francia), inv no 1022-1727. Colección Odescalchi, Palacio de Venecia, Roma (Leoherff 2008: 46 fig. 2a-b).

El contexto de Huelva es claramente 975925 AC (Mederos 1996: 96-98 tabla 1), pero creemos que el depósito amortizó estos metales al final del Bronce Final IIIA, 1050-950 AC. Por otra parte, el conjunto de Vila Cova de Perrinho lo asignamos a un momento avanzado del Bronce Final IIC, 1150-1050 AC, lo que nos situaría hacia $c a$. 1100 AC para un momento de inicio de estos cascos, sin descartar que comiencen hacia el $1150 \mathrm{AC}$, al comienzo de este periodo, después de la crisis de los Pueblos del Mar, cuando se reanudan los contactos con más intensidad entre el Atlántico y el Mediterráneo. 
Este casco atlántico para su dispersión utilizó tanto las vías fluviales como los ríos Rin y Sena, como el cabotaje costero en la Península Ibérica donde tienen una distribución próxima al litoral o en la entrada de ríos.

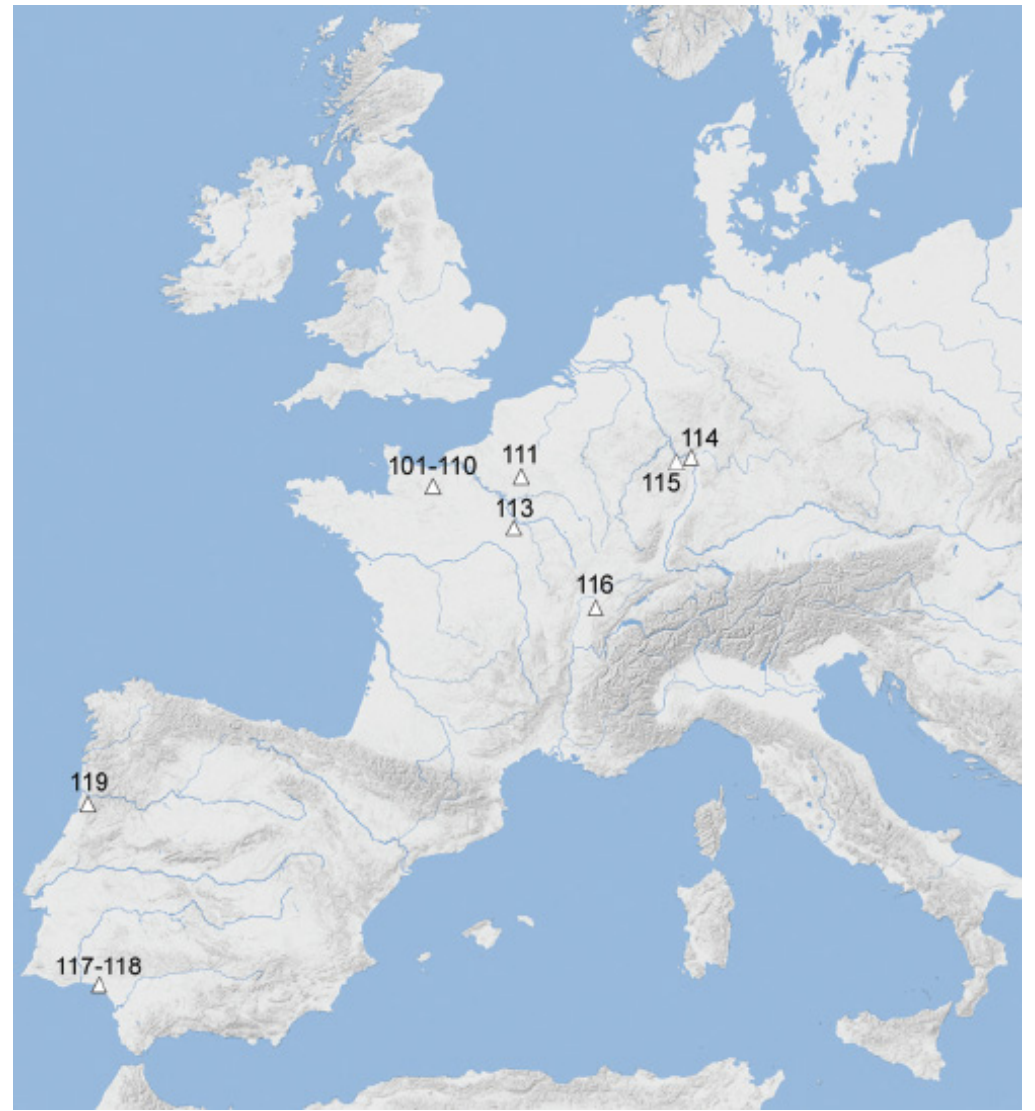

Fig. 14. Distribución de los cascos cónicos apuntados con cresta cóncava de tipo Bernières d’Ailly en Europa Occidental. 101-110) Bernières d'Ailly. 111) Armancourt. 113) Nemours. 114) Mainz-Kostheim. 115) Roxheim. 116) Larnaud. 117-118) Ría de Huelva. 119) Vila Cova de Perrinho (Mödlinger 2017: 119 fig. 2.24).

La fase final de los cascos se asocia con estelas del Suroeste donde el antropomorfo tiene un papel preeminente, en las cuales siguen utilizando el casco cónico apuntado con cresta cóncava triangular de de tipo Bernières d'Ailly, siendo el mejor ejemplo la estela de Setefilla pues se indica la cimera, debido al alto esquematismo de las representaciones. Estas estelas corresponden al Bronce Final IIIA, 1050-950 AC (Mederos 1997: 77 tabla 2), o Bronce Final IIIA Huelva (Brandherm y Mederos 2014: 84 fig. 5), 1050-930 AC (Brandherm 2007:
12; Harrison 2004: 14), 1050/1025-950/925 AC (Torres 2008: 76-77) o 940-750 AC (RuizGálvez 1998: 208).

\section{Agradecimientos}

Queremos agradecer las sugerencias de los dos evaluadores. También a Javier Jiménez Ávila que nos acompañó en la visita al Museo Arqueológico Municipal de Fundão y a su director, Pedro Salvado, por sus amables atenciones. 


\section{Bibliografía}

Almagro Basch, M. (1940): "El hallazgo de la Ría de Huelva y el final de la Edad del Bronce en el Occidente de Europa". Ampurias 2: 85-143.

- (1958): Depósito de la Ría de Huelva. Inventaria Archaeologica. España E-1. Fascículo 1-4. Instituto Español de Prehistoria-Dirección General de Bellas Artes. Madrid.

- (1966): Las estelas decoradas del Suroeste peninsular. Bibliotheca Praehistorica Hispana, VIII. Instituto Español de Prehistoria del Consejo Superior de Investigaciones Científicas. Madrid.

- (1970): "Dos nuevas estelas decoradas de la Andalucía Occidental”. En A. Beltrán (ed.): XI Congreso Nacional de Arqueología (Mérida, 1968). Secretaría General de los Congresos Arqueológicos Nacionales. Zaragoza: 315-331.

- (1974a): "Nuevas estelas decoradas de la Península Ibérica". En E. Ripoll Perelló y M. Llongueras (eds.): Miscelánea Arqueológica. XXV aniversario de los cursos internacionales de prehistoria y arqueología en Ampurias (1947-1971) (Ampurias, 1971). I. Diputación de Barcelona. Barcelona: 5-39.

- (1974b): "Depósito de bronces de la ría de Huelva". Huelva. Prehistoria y Antigüedad. Editora Nacional. Madrid: 213-220.

Almagro Gorbea, M. (1973): "Cascos del Bronce Final en la Península Ibérica". Trabajos de Prehistoria 30: 349-362.

- (1977): El Bronce Final y el Periodo Orientalizante en Extremadura. Bibliotheca Praehistórica Hispana XIV. Instituto Español de Prehistoria del Consejo Superior de Investigaciones Científicas. Madrid.

- (1989): "Arqueología e Historia Antigua: el proceso protoorientalizante y el inicio de los contactos de Tartessos con el Levante mediterráneo". Estudios sobre Antigüedad en homenaje al Profesor Santiago Montero Díaz. Anejos de Gerión 2: 277-288.

- (1998): “Precolonización’ y Cambio Socio-Cultural en el Bronce Atlántico”. En S. Oliveira Jorge (ed.): Existe uma Idade do Bronze Atlântico?. Trabalhos de Arqueologia 10. Lisboa: 81-100.

- y Sánchez Abal, J.L. (1978): “La estela decorada de Zarza de Montánchez (Cáceres)”. Trabajos de Prehistoria 35: 417-423.

Anónimo (1982): "Estela de Las Herencias (Toledo)". Museos 1: 88.

Aubet Semmler, Ma.E. (1997): "A propósito de una vieja estela”. Homenatge a la Prof. Dra. Milagro GilMascarell Bosca. II. Saguntum 30: 163-172.

Barceló Álvarez, J.A. (1989): Arqueología, Lógica y Estadística. Un análisis de las estelas decoradas de la Edad del Bronce en la Península Ibérica. Microfichas. Servei de Publicacions de la Universidad Autónoma de Barcelona. Bellaterra.

Bendala Galán, M. (1977): "Notas sobre las estelas decoradas del Suroeste y los orígenes de Tartessos". Habis 8: 177-205.

- (2000): Tartesios, iberos y celtas. Pueblos, culturas y colonizadores de la Hispania antigua. Temas de hoy. Madrid.

- (2013): "La génesis de Tarteso en la etapa 'precolonial' del Segundo milenio: notas para una discusión". En J. Campos y J. Alvar (eds.): Tarteso. El emporio del metal (Huelva, 2011). Almuzara. Córdoba: 123135.

-; Rodríguez Temiño, I. y Núñez, E. (1994): "Una nueva estela de guerrero tartésica de la provincia de Córdoba". En J. Mangas y J. Alvar (eds.): Homenaje a José Ma Blázquez. II. Serie Arys, 2. Ediciones Clásicas. Madrid: 59-69.

Bernier Luque, J. (1968): “Importante descubrimiento en el campo ibérico de Ategua. Una magnífica estela sepulcral céltica". Diario Regional del Movimiento, Córdoba, 3 de julio de 1968.

- (1968-69): "Una nueva estela grabada junto a las murallas ibéricas de Ategua en la provincia de Córdoba". Zephyrus 19-20: 181-185.

Blanco Freijeiro, A.; Luzón, J.Ma. y Ruiz Mata, D. (1969): "Panorama tartésico en Andalucía oriental". Tartessos y sus problemas. V Symposium Internacional de Prehistoria Peninsular (Jerez, 1968). Publicaciones Eventuales, 13. Instituto de Arqueología y Prehistoria. Universidad de Barcelona. Barcelona: 119-162.

Bonsor, G.E. y Thouvenot, R. (1928): Nécropole ibérique de Setefilla (Lora del Río, Sevilla). Bibliothèque de l’École des Hautes Études Hispaniques, 14. Bordeaux-Paris.

Bottaini, C. y Rodrigues, A. (2011a): "O conjunto de metais da Idade do Bronze de Vila Cova de Perrinho (Vale de Cambra, Portugal central) 50 anos após a sua descoberta". Estrat Crític 5 (3): 103-114. 
- (2011b): "O conjunto de metais de Vila Cova de Perrinho, Vale de Cambra. Caracterização química e revaliação dos contextos". Oppidum 6: 27-40.

Brandherm, D. (2007): Las espadas del Bronce Final de la Península Ibérica y Baleares. Prähistorische Bronzefunde IV (16). Franz Steiner. Stuttgart.

- (2011): "Bronzezeitliche Kamm- und Hörnerhelme. Überlegungen zu Ursprung, Verbreitung und Symbolischem Gehalt". En U.L. Dietz y A. Jockenhövel (eds.): Bronzen im Spannungsfeld zwischen praktischer Nutzung und symbolischer Bedeutung (Münster, 2008). Prähistorische Bronzefunde XX (13): 39-54.

- (2013): "Mediterranes, Atlantisches und Kontinentales in der bronze- und ältereisenzeitlichen Stelenkunst der Iberischen Halbinsel”. En G. Kalaitzoglou y G. Lüdorf (eds.): Petasos: Festschrift für Hans Lohmann. Mittelmeerstudien, 2. Wilhelm Fink-Ferdinand Scheningh Verlag. Paderborn: 131-148.

- (2016): "Stelae, funerary practice and group identities in the Bronze and Iron Ages of SW Iberia". En J.T. Koch y B. Cunliffe (eds.): Celtic from the West 3: Atlantic Europe in the Metal Ages: questions of shared language. Oxbow Books. Oxford: 179-200.

- y Mederos, A. (2014): "Un depósito de armas del Bronce Final de la cuenca media del Tajo: La Era, Lanzahita (Ávila)". Homenaje a la profesora Catalina Galán Saulnier. Anejos a Cuadernos de Prehistoria y Arqueología de la Universidad Autónoma de Madrid, 1: 79-85.

Bueno, P.; Piñón, F.; Torres, F.; Rodríguez, J.J. y Gutiérrez, F. (1984): “Tres nuevas estelas del Suroeste”. Revista de Estudios Extremeños, 40 (3): 477-483.

Celestino Pérez, S. (2001): Estelas de guerrero y estelas diademadas. La precolonización y formación del mundo tartésico. Bellaterra. Barcelona.

Cerdeño, $M^{\mathrm{a}}$.L. y Sagardoy, T. (2016): La necrópolis de Herrería I y II. Las fases culturales del Bronce Final II-III. Serie Arqueología y Patrimonio, 11. La Ergástula ediciones. Madrid.

Chapa, T. y Pereira, J. (2016): "La estela de guerrero de Las Herencias (Toledo)". Homenaje a Rodrigo de Balbín Behrmann. Arpi 4: 357-367.

Coffyn, A. (1985): Le Bronze Final Atlantique dans la Péninsule Ibérique. Publications du Centre Pierre Paris 11-Collection de la Maison des Pays Ibériques 20. De Boccard. Paris.

Coutil, L. (1927): "Le casque de Blainville (Meurthe-et-Moselle)". Bulletin de la Société Préhistorique Française 24: 362-366.

Dezsö, T. (1998): Oriental Influence in the Aegean and Eastern Mediterranean Helmet Traditions in the 9th-7th Centuries B.C.: The Patterns of Orientalization. British Archaeological Reports. International Series 691. Oxford.

- (2001): Near Eastern Helmets of the Iron Age. British Archaeological Reports. International Series 992. Oxford.

- (2012): The Assyrian Army I: The Structure of the Neo-Assyrian Army. 1. Infantry. 2. Cavalry and chariotry. Antiqua et Orientalia, 2-3. 2 vols. Budapest.

Díaz-Guardamino Uribe, M. (2010): Las estelas decoradas en la Prehistoria de la Península Ibérica. Tesis Doctoral. Universidad Complutense. Madrid.

-; García Sanjuán, L.; Wheatley, D. y Rodríguez Zamora, V. (2015): "RTI and the study of engraved rock art: A re-examination of the Iberian south-western stelae of Stefilla and Almadén de la Plata 2 (Seville, Spain)". Digital Applications in Archaeology and Cultural Heritage 2: 41-54.

-; García Sanjuán, L.; Wheatley, D.; Lozano, J.A.; Rogerio, M.A.; Krueger, M. and M.; Hunt, M.; Murillo, M. y Balsera, V. (2019): "Rethinking Iberian 'warrior' stelae: a multidisciplinary investigation of Mirasiviene and its connection to Setefilla (Lora del Río, Seville, Spain)". Archaeological and Anthropological Sciences, 2019: 1-30.

Domínguez de la Concha, C. y González Bornay, J.M. (2005): Estelas decoradas del Museo Arqueológico Provincial de Badajoz. Siglos VIII-V a.C. Consejería de Cultura. Junta de Extremadura. Badajoz.

Dothan, T. y Dothan, M. (1992): Peoples of the sea: the search for the Philistines. Scribner. New York.

Egg, M. y Tomedi, G. (2002): "Ein Bronzehelm au dem Mittelbronzezeitlichen depotfun vom Piller, Gemeinde Fliess, in Nordtirol”. Archäologisches Korrespondenzblatt 32 (4): 543-560.

Enríquez Navascués, J.J. y Celestino, S. (1984): "Nuevas estelas decoradas en la cuenca del Guadiana". Trabajos de Prehistoria 41: 237-250.

Fatás Cabeza, G. (1975): "Una estela de guerrero con escudo escotado en "V", aparecida en las Cinco Villas de Aragón”. Pyrenae 11: 165-169. 
Fernández-Miranda Fernández, M. (1986): “La estela de Las Herencias (Toledo)”. Estudios en homenaje al doctor Antonio Beltrán Martínez. Zaragoza: 463-473.

Ferrarese Ceruti, M.L; Vagnetti, L. y Lo Schiavo, L. (1987): "Minoici, micenei e ciprioti in Sardegna alla luce delle più recenti scoperte". En M.S. Balmuth (ed.): Studies in Sardinian Archaeology III. Nuragic Sardinia and the Mycenean World. British Archaeological Reports. International Series 387. Oxford: 7-34.

French, E. (1967): "Pottery from Late Helladic IIIB1 Destruction Contexts at Mycenae". The Annual of the British School at Athens 62: 149-193.

Gomá Rodríguez, J.L. (2018): El bronce final y la protocolonización en la Península Ibérica. Tesis Doctoral. Universidad Complutense. Madrid.

Gomes, M. Varela (1990) "O Oriente no Ocidente. Testemunhos iconográficos na Proto-história do Sul de Portugal: smiting gods ou deuses ameaçadores". Presencas orientalizantes em Portugal da Pre-historia ao periodo romano. Estudos Orientais 1: 53-106.

González Cordero, A. y Alvarado, M. de (1989-90): "Nuevas estelas decoradas en Extremadura". Norba 10: 59-66.

Hencken, H. (1955-56): "Fragmentos de cascos de Huelva". Ampurias 17-18: 224-228.

- (1971): The Earliest European Helmets. Bronze Age and Early Iron Age. Peabody Museum of Archaeology and Ethnology. Harvard University. Cambridge, Mass.

Henriques, F.; Lobato, M. y Caninas, J.C. (2012): "A estela de guerreiro (lusitano) de Zebros". Sabucale 4: $25-44$.

Homero (1991): Ilíada. Trad. E. Crespo Güemes. Biblioteca Clásica Gredos 150. Gredos. Madrid.

Kalb, Ph. (1980): "Zur atlantischen Bronzezeit in Portugal". Germania 58: 25-59.

Leoherff, A. (2008): "Les armes anciennes de la collection Odescalchi”. Jahrbuch des Römish-Germanischen Zentralmuseums 55: 43-79.

Lippert, A. (2010): "Spätbronzezeitliche Kammhelme an transalpinen Fernhandelsrouten (Mit einem Beitrag von Mathias Mehofer)". Archäologisches Korrespondenzblatt 40 (1): 49-65.

Lo Schiavo, F. (1989): "La Sardegna sulle rotte dell'Occidente. I. La Protostoria". Atti di Convegno di Studi sulla Magna Grecia, 29. Istituto per la Storia e l'Archeologia della Magna Grecia. Taranto, 1989 (1991): 99-161.

- (1991): "La Sardaigne et ses Relations avec le Bronze Final Atlantique”. En C. Chevillot y A. Coffyn (eds.): L'Age du Bronze Atlantique (Beynac, 1990). Association des Musées du Sarladais. Beynac-etCazenac: 213-226.

-; MacNamara, E. y Vagnetti, L. (1985): "Late Cypriot imports to Italy and their influence on local bronzework". Papers of the British School at Rome 53: 1-71.

Merhart, G. von (1940): "Zu den ersten Metallhelmen Europas". Bericht der Römisch-Germanischen Kommission 30: 4-42.

Mederos Martín, A. (1996): "La conexión levantino-chipriota. Indicios de comercio atlántico con el Mediterráneo Oriental durante el Bronce Final (1150-950 AC)”. Trabajos de Prehistoria 53 (2): 95-115.

- (1997): "Nueva cronología del Bronce Final en el Occidente de Europa". Complutum 8: 73-96.

- (1999): "Ex Occidente Lux. El comercio micénico en el Mediterráneo Central y Occidental (1625-1100 AC)". Complutum 10: 229-266.

- (2002): "Chipriotas o micénicos. Naves y cargamentos mixtos en el Mediterráneo Central (1300-1200 AC)". Academia de España en Roma 2002: 85-88.

- (2007): "La crisis del siglo XII a.C. Pueblos del Mar y Guerra de Troya ca. 1215-1175 a.C.". Spal 16: 93-153.

- (2008): "Carros micénicos del Heládico Final III en las estelas decoradas del Bronce Final II-III del Suroeste de la Península Ibérica”. En S. Celestino, N. Rafel y X.L. Armada (eds.): Contacto cultural entre el Mediterráneo y el Atlántico (siglos XII-VIII ANE): La Precolonización a debate. Escuela Española de Historia y Arqueología de Roma del CSIC. Serie Arqueológica, 11. Roma: 437-463.

- (2012): "El origen de las estelas decoradas del Suroeste de la Península Ibérica en el Bronce Final II (1325-1150 AC)". En J. Jiménez Ávila (ed.): Sidereum Ana II. El río Guadiana en el Bronce Final (Mérida, 2008). Anejos de Archivo Español de Arqueología, 42. Instituto de Arqueología de Mérida del C.S.I.C. Badajoz: 417-454.

- y Harrison, R.J. (1996): "Patronazgo y Clientela. Honor, Guerra y Festines en las Relaciones Sociales de Dependencia del Bronce Final Atlántico en la Península Ibérica”. Pyrenae 27: 31-52. 
- y Jiménez Ávila, J. (2016): "Las fíbulas de codo del Bronce Final en Extremadura y las representadas en las estelas del Suroeste de la Península Ibérica. A propósito de una nueva fíbula del Castillo de Guadajira (Lobón, Badajoz)". Homenaje a la profesora Concepción Blasco Bosqued. Anejos a Cuadernos de Prehistoria y Arqueología de la Universidad Autónoma de Madrid 2: 117-134.

Mendes, J. y Bizarro, J. (2015): "Arqueologia do Concelho de Fundao. Contributos para a carta Arqueologica". Eburobriga 8: 91-108.

Mehofer, M. (2011): "Die Kammhelme vom Typ Pass Lueg. Archäologische und archäometallurgische Untersuchungen zur spätbronzezeitlichen Handwerkstechnik". En A. Lippert (ed.): Die zweischaligen ostalpinen Kammhelme und verwandte Helmformen der späten Bronze- und frühen Eisenzeit. Archäologie in Salzburg 6. Salzburg: 119-130.

Milcent, P.-Y. (2012): Les temps des élites en Gaulle atlantique. Chronologie des mobiliers et rythmes de constitution des dépôts métalliques dans le contexte européen (XIIIe-VIIe s. av. J.-C.). Rennes.

Mödlinger, M. (2017): Protecting the Body in War and Combat. Metal Body Armour in Bronze Age Europe. Oriental and European Archaeology 6. Vienna.

Murillo, J.F.; Morena, J.A. y Ruiz Lara, D. (2005): "Nuevas estelas de guerrero procedentes de la provincia de Córdoba y Ciudad Real”. Romula 4: 7-46.

Naharro, A. (1976): "Las estelas decoradas de Extremadura". VI Coloquios de Históricos de Extremadura. Trujillo: 26-28.

Pflug, H. (1988): "Kyprische Helme". Antike Helme: Sammlung Lipperheide und andere Bestände des antikenmuseums Berlin. Römisch-Germanisches Zentralmuseum Monographien 14. Mainz: 27-41.

Ramón y Fernández Oxea, J. (1942): “Una estela prerromana del tipo de la de Solana de Cabañas". Archivo Español de Arqueología 15 (47): 334-337.

- (1950): "Lápidas sepulcrales de la Edad del Bronce en Extremadura". Archivo Español de Arqueología 23 (80): 293-318.

Rodríguez González, E. y González Bornay, J.M. (2018): "Una nueva estela de guerrero de Cabañas del Castillo (Cáceres)". Revista de Estudios Extremeños 74 (3): 1451-1474.

Rosso de Luna, M. (1898): "Losa sepulcral de Solana de Cabañas en el partido de Logrosan (Cáceres)". Boletín de la Real Academia de la Historia 32: 179-182.

Rovira Llorens, S. (1995): "Estudio arqueometalúrgico del depósito de la Ría de Huelva". Ritos de Paso y puntos de paso: La ría de Huelva en el mundo del Bronce Final Europeo. Complutum. Extra, 5. Universidad Complutense. Madrid: 33-57.

Ruiz-Gálvez Priego, Mª.L. (1998): La Europa Atlántica en la Edad del Bronce. Un viaje a las raíces de la Europa occidental. Crítica. Barcelona.

- y Galán, E. (2017): “From Shepherds to Heroes: Mediterranean Iconography of Power in the Far West". En M. Fotiadis, R. Laffineur, Y. Lolos y A. Vlachopoulos (eds.): Hesperos. The Aegean Seen From the West. $16^{\text {th }}$ International Aegean Conference (Ioannina, 2016). Aegaeum 41. Peeters Publishers. Liege: 53-60.

Sanabria Marcos, P.J. (2011): "La estela decorada del Puerto de Honduras (Cabezuela del Valle, Cáceres)". En R. Vilaça (ed.): Estelas e estatuas-menires da Pré à Proto-história. IV Jornadas Raianas (Sabugal, 2009). Sabugal: 369-388.

Santos, A.T.; Vilaça, R. y Marques, J.N. (2011): “As estelas do Baraçal, Sabugal (Beira Interior, Portugal)”. En R. Vilaça (ed.): Estelas e estatuas-menires da Pré à Proto-história. IV Jornadas Raianas (Sabugal, 2009). Sabugal: 319-342.

Schauer, P. (1979-80): “Urnenfelderzeitliche Helmformen und ihre Vorbilder". Fundberichte Hessen 1920: $521-543$

- (1983): "Orient im spätbronze- und früheisenzeitlichen Occident Kulturbeziehugen zwischen der Iberischen Halbinsel und der vorderen Orient während des spätens zweiten und des ersten Drittels des I. Jahrtausends v. Ch.”. Jahrbuch des Römish-Germanischen Zentralmuseums 30: 175-194.

Sperber, L. (2006): "Bronzezeitliche Flussdeponierungen aus dem Altrhein bei Roxheim, Gde. Bobenheimroxheim, Lkr. Ludwigshafen -ein Vorberich". Archäologisches Korrespondenzblatt 36: 195-214.

- (2011): "Bronzene Schutzwaffen in Gräbern der Urnenfelderkultur. Beinschienen- und Helm(?) fragmente aus dem Gräberfeld Volders in Nordtirol". Bayerische Vorgeschichtsblätter 76: 5-45.

Tejera, A. y Fernández Rodríguez, J. (2012): Los dioses de los tartesios. Bellaterra Arqueología. Barcelona. Tomedi, G. y Egg, M. (2014): "Zur Chronologie bronze- und früheisenzeitlicher Kammhelme". Archäologisches Korrespondenzblatt 44 (1): 41-57. 
Torres Ortiz, M. (2008): “Los 'tiempos' de la precolonización”. En S. Celestino, N. Rafel y X.L. Armada (eds.): Contacto cultural entre el Mediterráneo y el Atlántico (siglos XII-VIII ANE): La Precolonización a debate. Escuela Española de Historia y Arqueología de Roma del CSIC. Serie Arqueológica 11. Roma: 59-91.

- (2012): "La precolonización en Extremadura". En J. Jiménez Ávila (ed.): Sidereum Ana II. El río Guadiana en el Bronce Final (Mérida, 2008). Anejos de Archivo Español de Arqueología 42. Instituto de Arqueología de Mérida del C.S.I.C. Badajoz: 455-474.

Vagnetti, L. (2000): "Western Mediterranean Overview: Peninsular Italy, Sicily and Sardinia at the Time of the Sea Peoples". En E.D. Oren (ed.): The Sea Peoples and their World. A Reassessment (Philadelphia 1995). University of Pennsylvania Museum Monograph 108. Philadelphia: 305-323.

Vaquerizo Gil, D. (1985): "Dos nuevas estelas de guerrero en la provincia de Badajoz". En A. Beltrán (ed.): XVII Congreso Nacional de Arqueología (Logroño, 1983). Secretaría General de los Congresos Arqueológicos Nacionales. Zaragoza: 465-472, 480-481.

Vilaça, R.; Santos, A.T.; y Gomes, S. de Melo (2011): “As estelas de 'Pedra da Atalaia' (Celorico da Beira, Guarda) no seu contexto geo-arqueológico". En R. Vilaça (ed.): Estelas e estatuas-menires da Pré à Proto-história. IV Jornadas Raianas (Sabugal, 2009). Sabugal: 293-318.

-; Rosa, J. Mendes; Bizarro, J.; Pires, H. y Baptista, P. (e.p.): "Nova estela, nova história. Um referencial do Bronze Final na Cova da Beira (Telhado, Fundão, Portugal)". Images in Stone in the Prehistory and Protohistory (Braga, 2016). Poster.

Villaseca Díaz, F. (1993): "La estela decorada y la espada de lengua de carpa del bronce final de AlmargenMálaga”. Baética 15: 217-226. 